\title{
DISPONIBILIDAD DE INFRAESTRUCTURA Y RECURSOS TECNOLÓGICOS EN EL SISTEMA ESCOLAR DE EDUCACIÓN BÁSICA DEL DISTRITO METROPOLITANO DE QUITO
}

\author{
Juan Coronel
}

\section{RESUMEN}

La combinación curricular de los medios tecnológicos (informáticos, audiovisuales y de la comunicación en general) y el aprovechamiento de las ventajas didácticas no resulta una labor sencilla. El docente necesita determinadas destrezas e ideas técnicas, ha de estar enterado sobre los materiales disponibles y sobre cómo usarlos didácticamente, y precisa recursos e infraestructura para desarrollar las actividades educativas con sus estudiantes. También es necesario tiempo para: preparar todas estas actividades, planificar, evaluar su uso, etc.

El problema que presume el uso de los medios informáticos y audiovisuales en los procesos de enseñanza y aprendizaje, las instituciones educativas que quieren iniciar o ampliar su utilización por parte del cuerpo docente han de procurar una buena organización de estos recursos. Esta organización generalmente supone el montaje de aulas de recursos que faciliten la utilización, el control y el almacenamiento de estos materiales.

En la distribución de los recursos tecnológicos de un centro logramos diferenciar tres tipos de elementos materiales:

La infraestructura física. Se considera:

- El área física adecuada para el uso y almacenamiento de los recursos: aulas, almacenes, bodegas, etc.

- Las instalaciones: iluminación, enchufes, ventilación, aislamiento, sistemas de seguridad.

- Los materiales adicionales: mesas, armarios, sillas...

Los aparatos tecnológicos. Son aquellos aparatos obligatorios para poder usar los materiales curriculares que se presentan como soporte tecnológico. Por ejemplo:

- Computadoras, impresoras, conexiones y otros recursos informáticos.

- Televisión, Televisión por cable, Televisión satelital. 
- Retro-proyectores, proyectores de diapositivas, cámaras fotográficas.

- Casetes, cadenas musicales, altavoces, micros.

Materiales curriculares. Son los materiales que, en conjunto con sus guías didácticas, contienen la información. Su aplicación requiere el uso de algunos aparatos tecnológicos. Entre los materiales curriculares que necesitan soporte tecnológico se puede destacar:

- Software informático.

- Diapositivas, transparencias.

- Programas de vídeo.

- Discos compactos.

Esta investigación tiene como objetivo fundamental realizar una descripción de la situación de las Escuelas del Distrito Metropolitano de Quito en el año 2011, en los siguientes ámbitos de estudio: infraestructura y recursos tecnológicos. Una parte importante de este estudio es determinar los contrastes existentes entre las Instituciones Educativas de este territorio.

\begin{abstract}
The curricular combination of the technological resources (computer, audiovisuals and the communications in general) and the didactics aids provided by them, seems not to be an easy task. The teachers need certain skills as well as technical ideas. They need to be well trained on the uses of the available materials and have a wide knowledge about the didactic use of them. It is also mandatory to provide the institutions with an appropriate infrastructure to develop the educative activities along with the students. So forth in order to prepare, plan and asses the correct application of such activities time is required.
\end{abstract}

The problem comes out in the uses of the computer and audiovisuals means during the teaching learning process. The educative institutions, in an attempt to initiate or increase the use of these means, should provide teachers with a rightful organization of these resources. Such organization is related to the provision of source rooms which facilitate the utilization, control and storage of these materials.

In the distributions of the technological resources of an institution there are three types of material elements.

The physic infrastructure: it is considered: 
- The physic area arranged for the use and storage of the resources: classrooms, stores, shops, etc.

- The facilities: illumination, plugs, air condition, security systems.

- The additional materials: tables, chairs, closets, etc.

The technological apparatus. They are the mandatory apparatus in order to utilize the curricular materials presented as technological support. For instance:

- Computers, printers, connections, and any other informatics resources

- TV, cable TV, satellite TV.

- LCD projectors, overhead projectors, camera.

- Cassettes, devises to store music, speakers, microphones.

Curricular materials. They are materials that together with their didactic guides contain the information. Its application requires the use of technological apparatus. For instance:

- Informative software

- Slides

- Compact discs

- Video programs

The aim of this research is to map the current situation of the schools within the Metropolitan District of Quito in the year 2011 in both infrastructure and technological resources fields. A very important component of this study is to determine the existent contrast among the Educative Institutions located within this territory.

\section{Palabras clave}

TICs, educación, recursos, infraestructura. 


\section{INTRODUCCIÓN}

Vivimos en un periodo abundante de elaboración de estudios evaluativos, de informes de investigación y de publicaciones académicas que tienen como objeto de análisis el grado de disponibilidad, uso e impacto de las tecnologías de la información y comunicación sobre el sistema escolar. Este aumento importante de la producción intelectual sobre este problema no sólo ocurre en los países desarrollados, sino que también en el contexto académico de los países en vías de desarrollo, en estos últimos años, se ha generado una notable producción de trabajos que han explorado cómo los profesores perciben y piensan con relación a estas tecnologías, así como su uso en el entorno escolar.

Sin embargo, carecemos de un marco teórico suficientemente sistematizado que explique el conjunto de fenómenos y factores asociados no sólo con la generalización de las TICs a gran escala en los sistemas escolares, sino también que explique o conceptualice cómo se generan procesos de innovación y mejora educativa trabajando con tecnología en los centros y aulas. Esto es, tenemos numerosa información empírica sobre las TICs en las escuelas, pero nos falta cimentar una teoría sobre este fenómeno específico de la realidad escolar que nos permita comprender qué sucede cuando esta tecnología entra en las escuelas, las causas de la resistencia de los docentes a integrar estas tecnologías en su práctica, o cómo implementar exitosamente estrategias de incorporación escolar de las TICs en un determinado contexto nacional o regional.

\section{OBJETIVOS}

\section{Objetivo General}

El objetivo de este trabajo es dar una descripción de la situación de las Escuelas del DMQ en diferentes ámbitos: infraestructura y tecnología básica; orientados a determinar el acceso a servicios: comunicaciones, Internet, recursos educativos.

\section{Objetivos específicos}

- Tomar, organizar, presentar, analizar y mostrar conclusiones sobre la situación actual de las Instituciones educativas de nivel básico del cantón Quito

- Detectar los grupos escolares más vulnerables en el territorio del DMQ, en diferentes áreas, y así aportar a la elección de proyectos puntuales. 


\section{MATERIALES Y MÉTODOS}

\section{TAMAÑO DE LA MUESTRA}

Determine qué tamaño de muestra necesita para obtener una representación precisa de la población total de su objetivo de grupo con nuestra calculadora de tamaño de muestra.

\section{Terminología de tamaño de muestra}

- Nivel de confianza

El nivel de confianza le dice cuán "seguro" puede estar que su población seleccione cierta respuesta.

- Intervalo de confianza

El intervalo de confianza es el rango +/- que se suma a la respuesta que usted recibe de su muestra para proporcionar un rango de porcentaje que describa con precisión la respuesta probable de la población.

- Población

Cuanto mayor sea la muestra en comparación con la población total, tanto más precisas serán las respuestas. Sin embargo, si la población es muy grande o se desconoce, puede dejar este dato en blanco, ya que en términos matemáticos las diferencias son estadísticamente mínimas.

Por ejemplo, si usted realiza una muestra de 1.000 personas con un nivel de confianza del 95\% y un intervalo de confianza de 3, y el 70\% elige la Marca A, usted puede tener un 95\% de certeza de que entre el 67\% y el 73\% (70\% +/- 3) elegiría la Marca A.

Terminología de nivel de confianza

- Tamaño de muestra

El tamaño de muestra es el fragmento de personas más grande dentro de una población que usted ha elegido para la encuesta. Cuanto mayor sea la muestra en comparación con la población total, tanto más precisas serán las respuestas.

- Porcentaje

Es el porcentaje de su muestra que respondió de una forma específica. Si el 90\% de su muestra elige la Marca A, puede estar bastante seguro de que la población elegiría la Marca A, mientras que si el 51\% de su muestra elige la Marca A, es mayor la probabilidad de que esto sea incorrecto. Fundamental- 
mente puede tener más confianza en las respuestas extremas que en las respuestas intermedias. Manténgalo en el 50\% para obtener el intervalo de confianza más útil.

Calculadora de tamaño de muestra
Nivel de confianza:
Intervalo de confianza:
$\begin{aligned} & \text { Población: } \\ & \text { (deje en blanco si el número } \\ & \text { es demasiado alto o si lo } \\ & \text { desconoce) }\end{aligned}$
$\begin{aligned} & \text { Tamaño de muestra } \\ & \text { necesario: }\end{aligned}$

\section{Muestra estratificada}

Implica el uso deliberado de submuestras para cada estrato o categoría que sea importante en la población. 


\begin{tabular}{|c|c|c|}
\hline PARROQUIA & $\mathbf{N}^{\circ}$ ESCUELAS & MUESTRA \\
\hline Alangasí & 9 & 2 \\
\hline Belisario Quevedo & 35 & 6 \\
\hline Calderón (Carapungo) & 29 & 6 \\
\hline Carcelén & 37 & 7 \\
\hline Centro Histórico & 153 & 31 \\
\hline Comité del Pueblo & 131 & 26 \\
\hline Cotocollao & 110 & 22 \\
\hline Chilibulo & 2 & 0 \\
\hline Chillogallo & 94 & 19 \\
\hline Chimbacalle & 46 & 9 \\
\hline Cochapamba & 95 & 19 \\
\hline Condado & 7 & 1 \\
\hline Cumbayá & 3 & 1 \\
\hline Guamaní & 79 & 16 \\
\hline Iñaquito & 18 & 4 \\
\hline Itchimbia & 80 & 16 \\
\hline Jipijapa & 10 & 2 \\
\hline Kennedy & 38 & 8 \\
\hline La Argelia & 11 & 2 \\
\hline La Concepción & 24 & 5 \\
\hline La Ecuatoriana & 21 & 4 \\
\hline La Ferroviaria & 24 & 5 \\
\hline La Libertad & 29 & 6 \\
\hline La Magdalena & 71 & 14 \\
\hline La Mena & 15 & 3 \\
\hline Llano Chico & 2 & 0 \\
\hline Mariscal Sucre & 22 & 4 \\
\hline Ponceano & 34 & 7 \\
\hline Puengasí & 107 & 22 \\
\hline Quitumbe & 31 & 6 \\
\hline Rumipamba & 43 & 9 \\
\hline San Antonio & 6 & 1 \\
\hline San Bartolo & 34 & 7 \\
\hline San Isidro del Inca & 32 & 6 \\
\hline San Juan & 24 & 5 \\
\hline Solanda & 2 & 0 \\
\hline Turubamba & 7 & 1 \\
\hline Zambiza & 2 & 0 \\
\hline Amaguaña & 2 & 0 \\
\hline TOTAL & 1519 & 306 \\
\hline
\end{tabular}


ING. JUAN CORONEL

\begin{tabular}{|c|c|c|}
\hline FISCAL & $\mathbf{N}^{\circ}$ ESCUELAS & $\begin{array}{c}\text { MUESTRA } \\
\text { AL } 7 \%\end{array}$ \\
\hline Alangasí & 1 & 0 \\
\hline Belisario Quevedo & 12 & 3 \\
\hline Calderón (Carapungo) & 3 & 1 \\
\hline Carcelén & 16 & 4 \\
\hline Centro Histórico & 51 & 13 \\
\hline Comité del Pueblo & 50 & 12 \\
\hline Cotocollao & 43 & 11 \\
\hline Chilibulo & 2 & 0 \\
\hline Chillogallo & 41 & 10 \\
\hline Chimbacalle & 28 & 7 \\
\hline Cochapamba & 11 & 3 \\
\hline Condado & 5 & 1 \\
\hline Cumbayá & 1 & 0 \\
\hline Guamaní & 23 & 6 \\
\hline Iñaquito & 12 & 3 \\
\hline Itchimbia & 26 & 6 \\
\hline Jipijapa & 3 & 1 \\
\hline Kennedy & 17 & 4 \\
\hline La Argelia & 7 & 2 \\
\hline La Concepción & 14 & 3 \\
\hline La Ecuatoriana & 7 & 2 \\
\hline La Ferroviaria & 6 & 1 \\
\hline La Libertad & 6 & 1 \\
\hline La Magdalena & 41 & 10 \\
\hline La Mena & 7 & 2 \\
\hline Llano Chico & 1 & 0 \\
\hline Mariscal Sucre & 4 & 1 \\
\hline Ponceano & 4 & 1 \\
\hline Puengasí & 38 & 9 \\
\hline Quitumbe & 4 & 1 \\
\hline Rumipamba & 4 & 1 \\
\hline San Antonio & 1 & 0 \\
\hline San Bartolo & 10 & 2 \\
\hline San Isidro del Inca & 9 & 2 \\
\hline San Juan & 9 & 2 \\
\hline Solanda & 1 & 0 \\
\hline Turubamba & 5 & 1 \\
\hline Zambiza & 1 & 0 \\
\hline Amaguaña & 0 & 0 \\
\hline TOTAL & 524 & 129 \\
\hline
\end{tabular}




\begin{tabular}{|c|c|c|}
\hline PARTICULAR & $\mathbf{N}^{\circ}$ ESCUELAS & $\begin{array}{c}\text { MUESTRA AL } \\
7 \%\end{array}$ \\
\hline Alangasí & 8 & 1 \\
\hline Belisario Quevedo & 23 & 4 \\
\hline Calderón (Carapungo) & 26 & 5 \\
\hline Carcelén & 21 & 4 \\
\hline Centro Histórico & 102 & 18 \\
\hline Comité del Pueblo & 81 & 14 \\
\hline Cotocollao & 67 & 12 \\
\hline Chilibulo & 0 & 0 \\
\hline Chillogallo & 53 & 9 \\
\hline Chimbacalle & 18 & 3 \\
\hline Cochapamba & 84 & 15 \\
\hline Condado & 2 & 0 \\
\hline Cumbayá & 2 & 0 \\
\hline Guamaní & 56 & 10 \\
\hline Iñaquito & 6 & 1 \\
\hline Itchimbia & 54 & 10 \\
\hline Jipijapa & 7 & 1 \\
\hline Kennedy & 21 & 4 \\
\hline La Argelia & 4 & 1 \\
\hline La Concepción & 10 & 2 \\
\hline La Ecuatoriana & 14 & 2 \\
\hline La Ferroviaria & 18 & 3 \\
\hline La Libertad & 23 & 4 \\
\hline La Magdalena & 30 & 5 \\
\hline La Mena & 8 & 1 \\
\hline Llano Chico & 1 & 0 \\
\hline Mariscal Sucre & 18 & 3 \\
\hline Ponceano & 30 & 5 \\
\hline Puengasí & 69 & 12 \\
\hline Quitumbe & 27 & 5 \\
\hline Rumipamba & 39 & 7 \\
\hline San Antonio & 5 & 1 \\
\hline San Bartolo & 24 & 4 \\
\hline San Isidro del Inca & 23 & 4 \\
\hline San juan & 15 & 3 \\
\hline Solanda & 1 & 0 \\
\hline Turubamba & 2 & 0 \\
\hline Zambiza & 1 & 0 \\
\hline Amaguaña & 2 & 0 \\
\hline TOTAL & 995 & 177 \\
\hline
\end{tabular}




\begin{tabular}{|c|c|c|c|}
\hline \multicolumn{4}{|c|}{$95 \%$ de confiabilidad } \\
\hline & $5 \%$ & $\begin{array}{c}7 \% \\
\text { intervalo de confianza }\end{array}$ & $6 \%$ \\
\hline Fiscal & 222 & 129 & 177 \\
\hline Particular & 280 & 177 & 210 \\
\hline TOTAL & 502 & 306 & 387 \\
\hline
\end{tabular}

Nota: 306 Instituciones Educativas visitadas, cuya información la proporcionó cada Director.

La encuesta es el método de la investigación que se ha utilizado y sirve para obtener información específica de la muestra (ver tabla xxx) de la población mediante el uso de cuestionarios estructurados que se utilizan para obtener datos precisos de las personas (directores) encuestadas.

La información fue procesada y tabulada usando LimeSurvey, es una aplicación distribuida bajo licencia GPL extremadamente útil para quien trabaja recogiendo datos y analizando resultados usando encuestas.

\section{RESULTADOS}

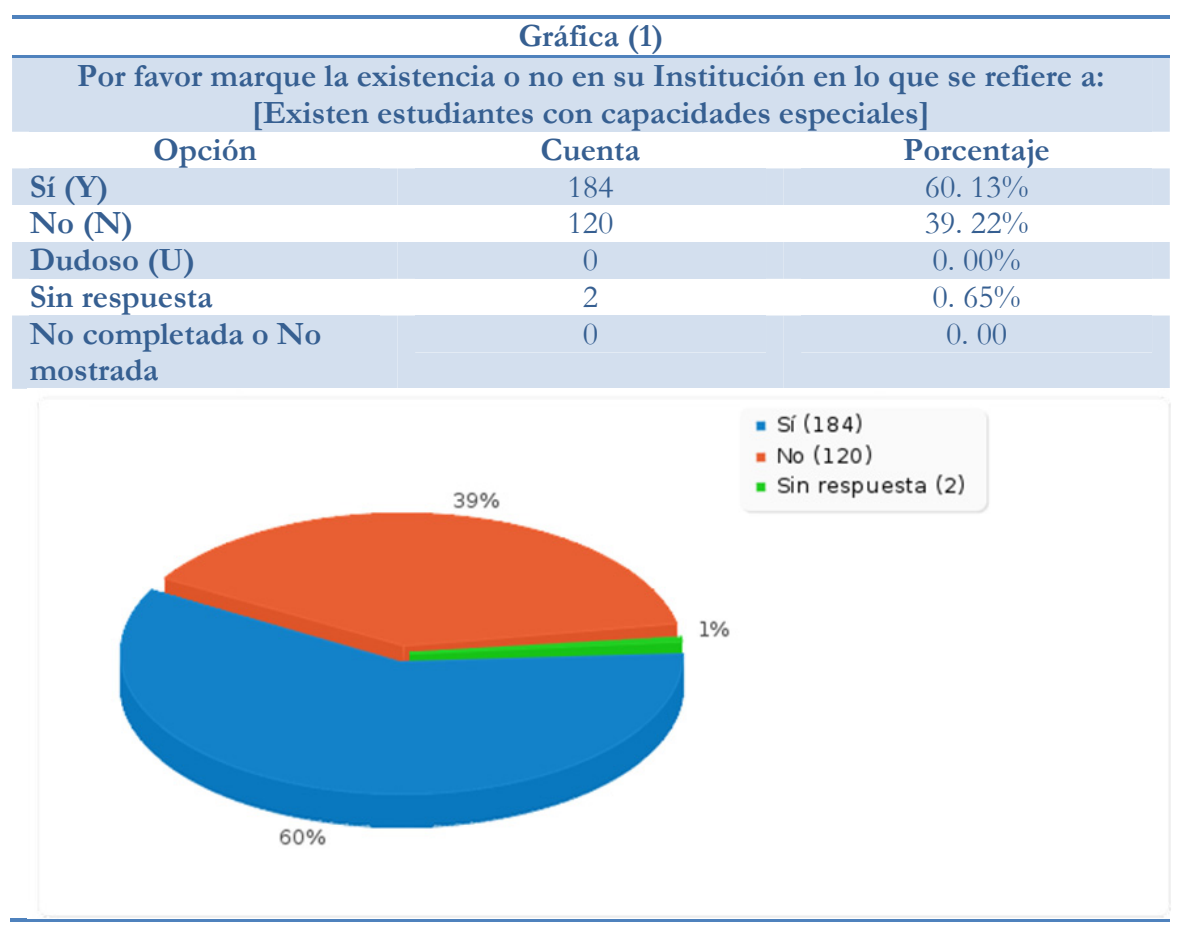

En estos espacios de innovaciones y cambios educativas constantes, los educadores se ven desafiados a una demanda social de mayor calidad de educación, pero están faltos de los recursos pedagógi- 
cos (no fueron formados para atender a alumnos de múltiples condiciones socio cognitivas, intelectuales y sociales), instrumentales, técnicas y económicas para responder eficazmente a un proceso de enseñanza y aprendizaje cada vez más complejo, caracterizado, entre otros aspectos ya señalados, por la diversidad social y el perfil heterogéneo de los estudiantes.

De aquí que el gobierno ha asumido la responsabilidad política de impulsar acciones y destinar recursos para atender esta situación.

\begin{tabular}{|c|c|c|}
\hline \multicolumn{3}{|c|}{ Gráfica (2) } \\
\hline \multicolumn{3}{|c|}{$\begin{array}{l}\text { Por favor marque la existencia o no en su Institución en lo que se refiere a: } \\
\text { [Dispone de iluminación en las aulas] }\end{array}$} \\
\hline Opción & Cuenta & Porcentaje \\
\hline Sí (Y) & 300 & $98.04 \%$ \\
\hline No $(\mathbf{N})$ & 3 & $0.98 \%$ \\
\hline Dudoso (U) & 0 & $0.00 \%$ \\
\hline Sin respuesta & 3 & $0.98 \%$ \\
\hline \multirow[t]{3}{*}{ No completada o No mostrada } & 0 & $0.00 \%$ \\
\hline & $\begin{array}{l}\text { - Si ( } \\
\text { = No } \\
\text { " Sin }\end{array}$ & \\
\hline & & \\
\hline
\end{tabular}

Las instalaciones de iluminación de las distintas dependencias que componen una institución educativa, deben estar dotadas de sistemas que proporciones un entorno visual confortable y suficiente, según las muy variadas actividades que se van a desarrollar. Si aplicamos calidad al diseño, instalación y mantenimiento de todos aquellos elementos que intervienen la obtención de una buena iluminación, obtendremos los resultados de confort visual requeridos, todo esto garantizando la máxima eficiencia energética y por tanto, los mínimos costos de explotación. 


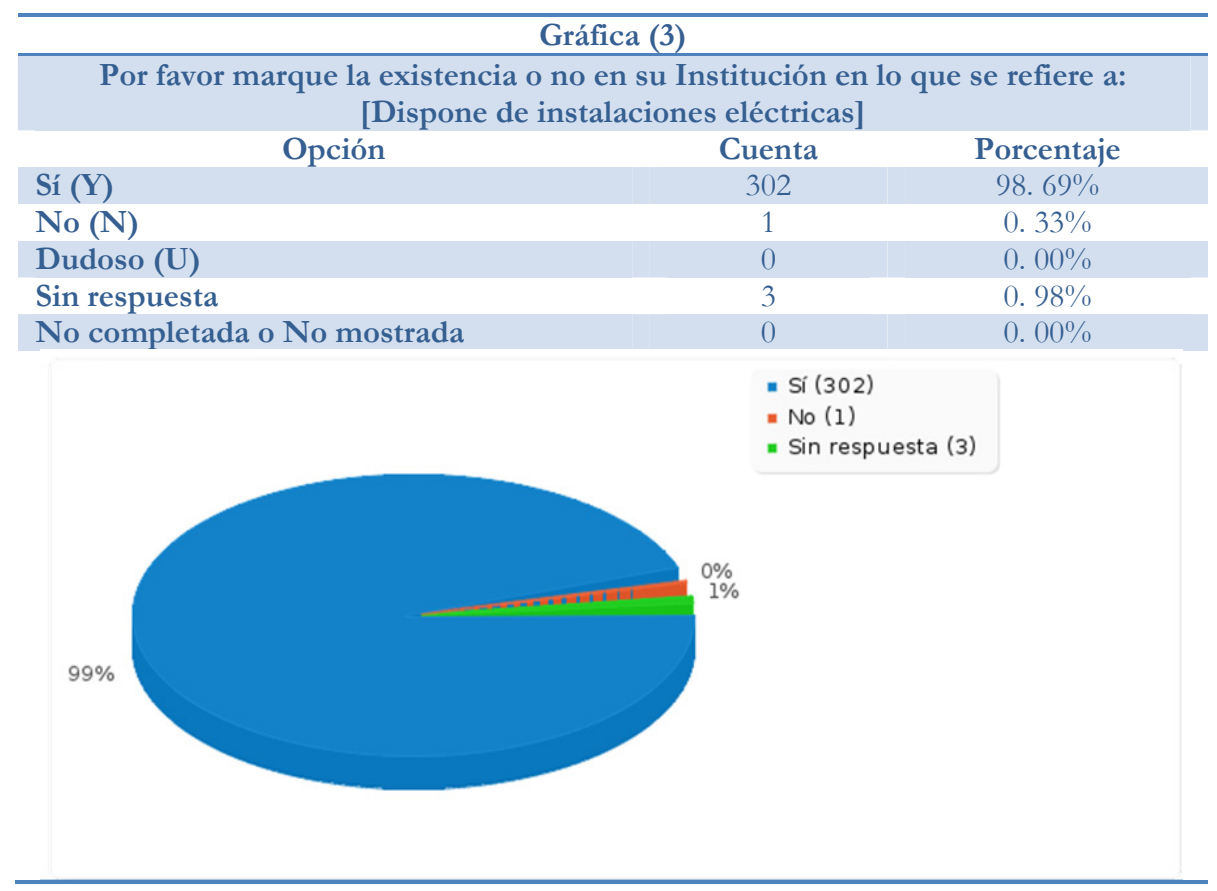

Aulas de computadoras para que los utilicen libremente los estudiantes y enchufes para las portátiles. Repartidos en aulas, salas y bibliotecas de estudio y otros espacios específicos debe haber computadoras suficientes para que el alumnado pueda acceder a ellas cuando lo necesiten. Si se promueve el uso de portátiles personales entre los estudiantes, se necesitarán menos aulas de computadoras. Promover el trabajo en grupo más allá de las clases presenciales con el profesorado; y hoy en día la mayor parte de estos trabajos exigen el uso de un computador. 


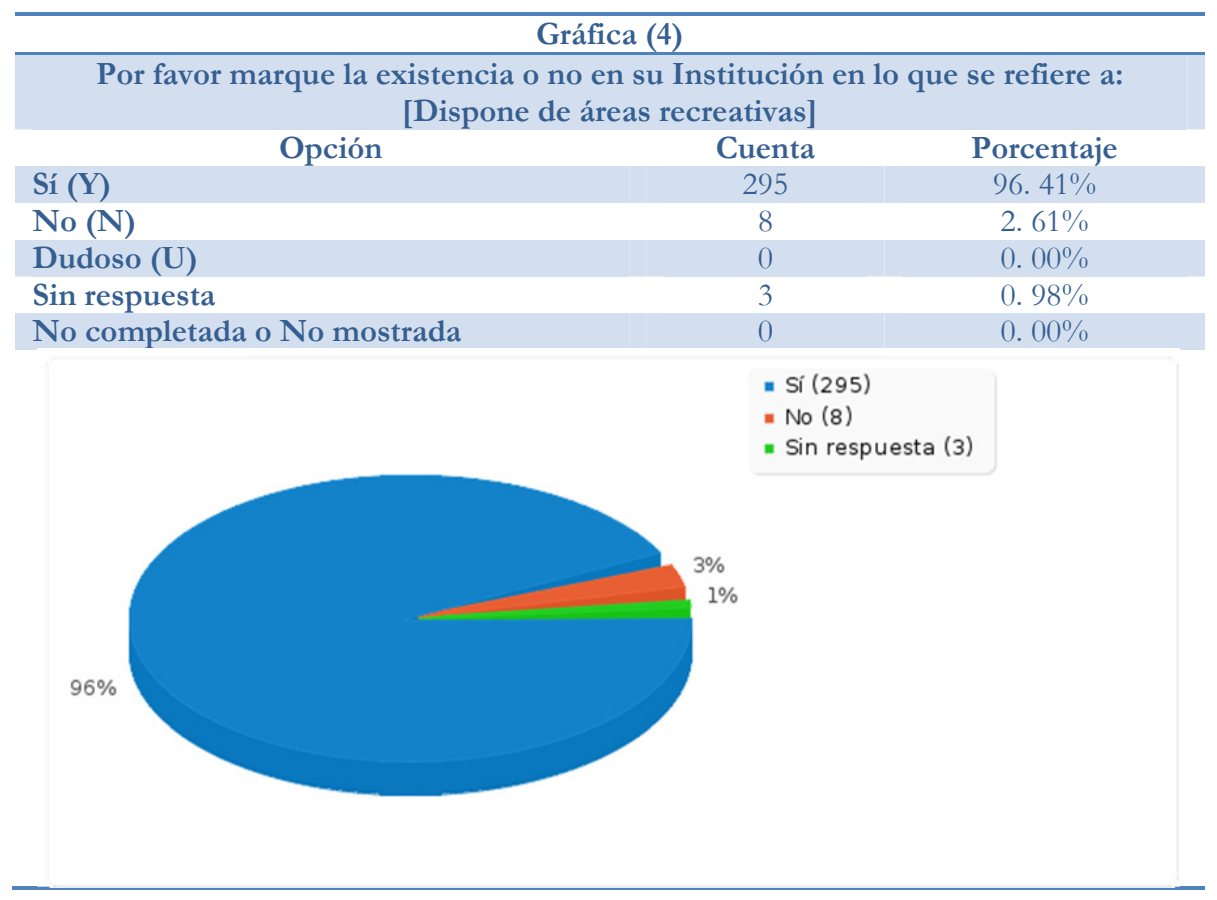

Efectivamente la recreación tiende a hablarse en dos directrices: La primera, asume a la recreación como una práctica institucionalizada del tiempo libre cuyas funciones principales son la alegría, el placer y el descanso. Por lo tanto la educación formal concede a la recreación un lugar como actividad extracurricular (juegos, dinámicas y prácticas que permiten a los estudiantes salir del automatismo escolar). Para la segunda directriz, se le asigna a la recreación funciones de desarrollo, en la medida que se atribuye a las prácticas recreativas un valor pedagógico que se articula a procesos educativos de transformación socio cultural. 


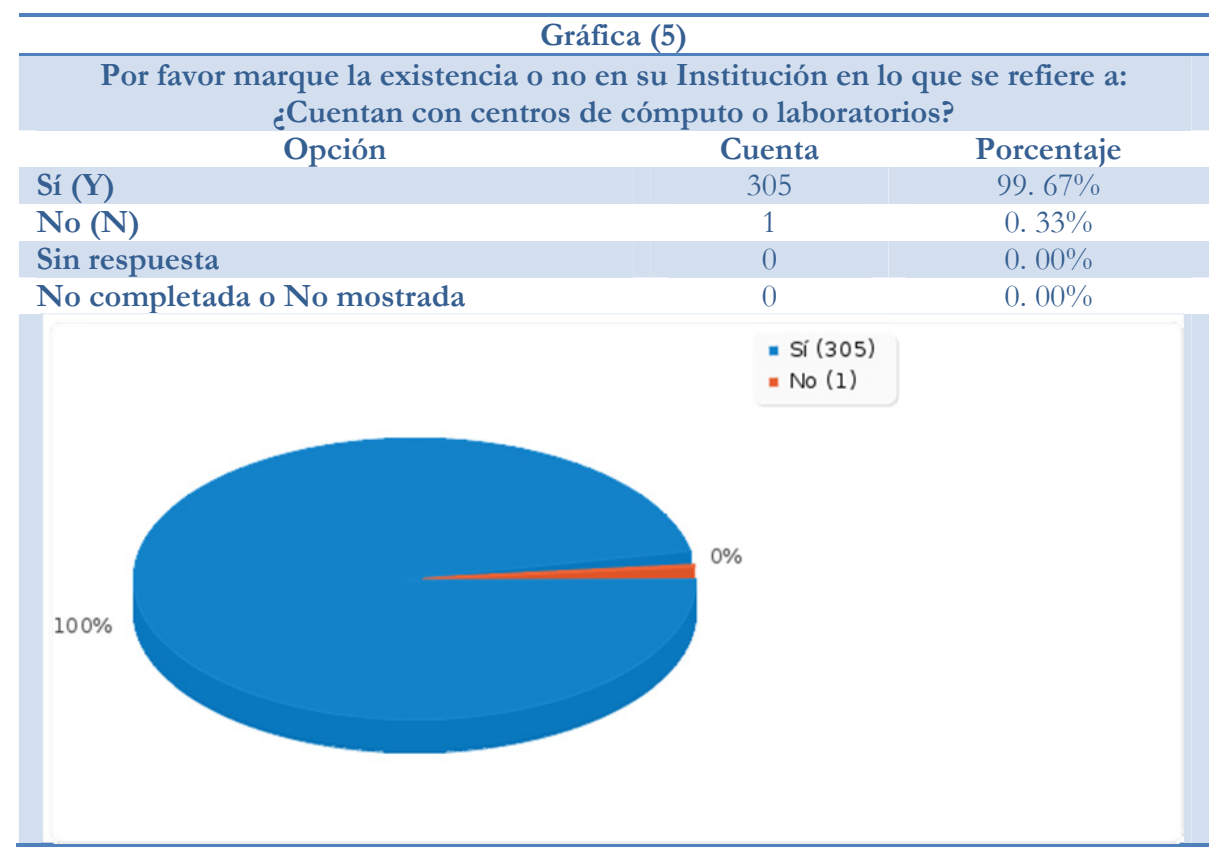

Es evidente la importancia de la caída del precio de las computadoras, muchas escuelas han podido incorporar diversos recursos tecnológicos, como computadoras y otros recursos. Inclusive, algunas de ellas han sido el centro de programas que promueven una computadora para cada alumno. Disponer de más computadoras en las escuelas permite que los docentes utilicen estos medios a su propio ritmo y con un sistema de programación de actividades que se ajuste a sus requerimientos. Aquellos, partidarios de una computadora por alumno ven el uso de esta tecnología como una oportunidad de modificar la forma de elaboración de la enseñanza tradicional. Creen que es posible lograr un enfoque constructivista enfocado en el estudiante, quien puede aprender y prosperar a su propio ritmo. 


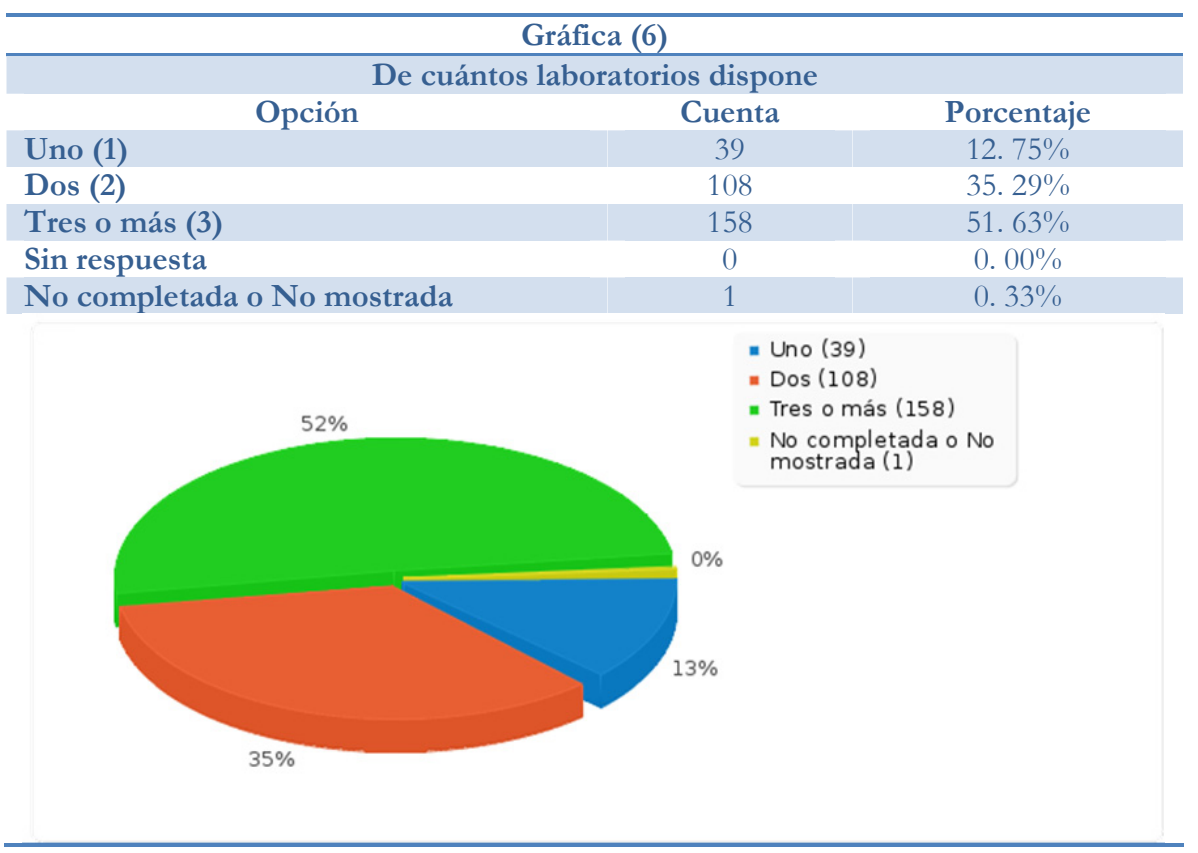

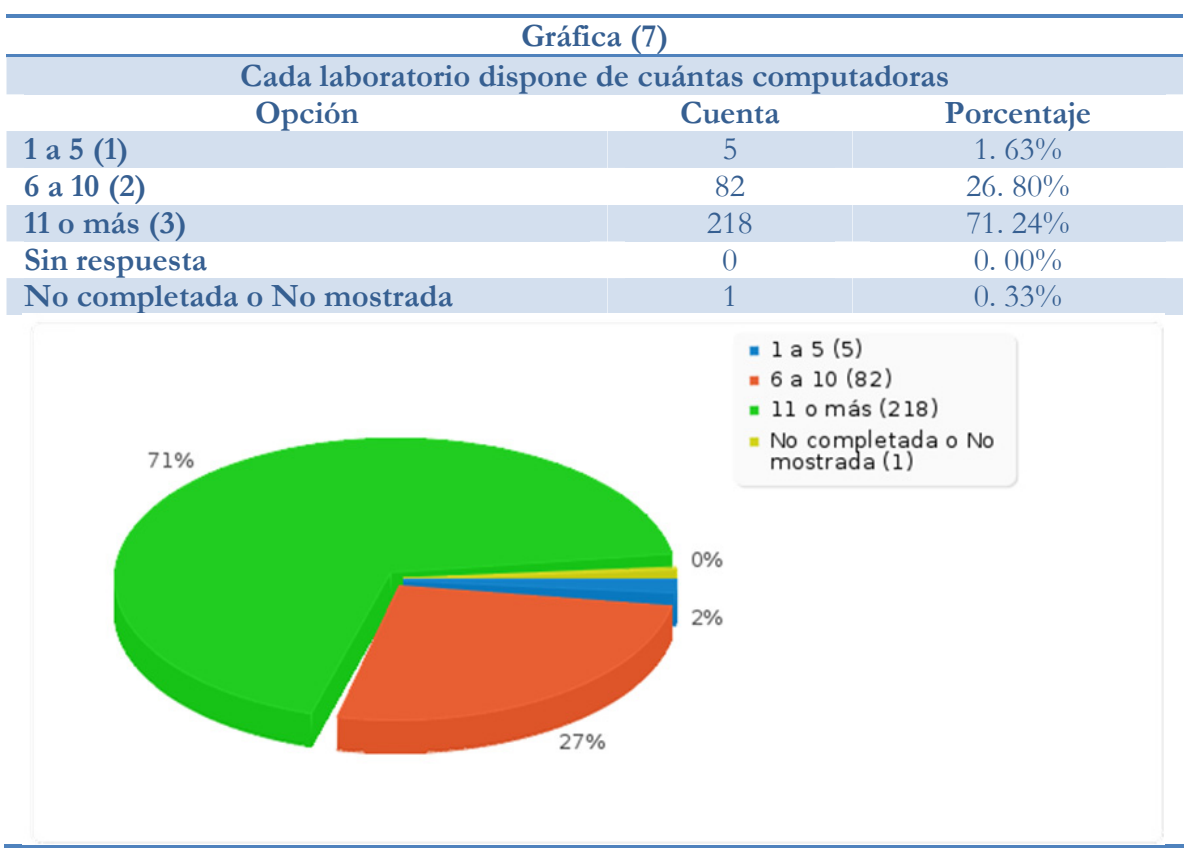




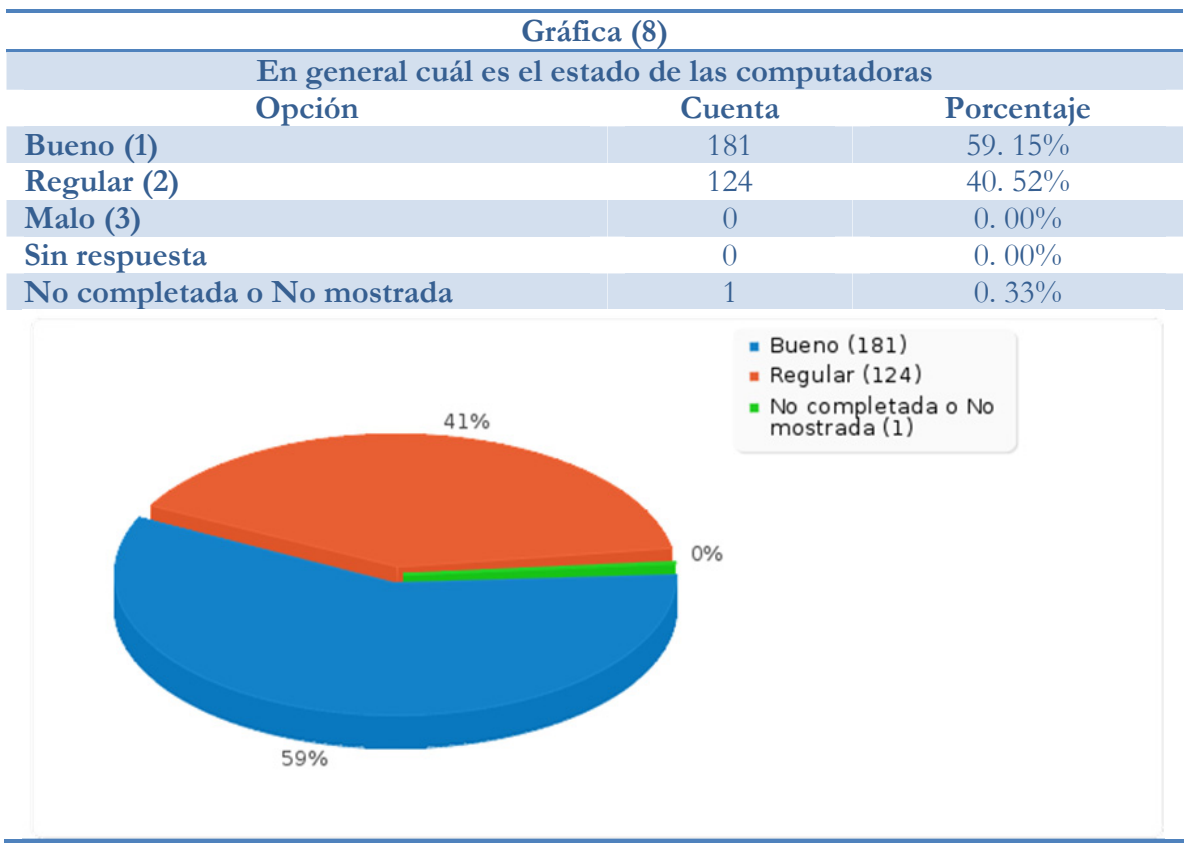

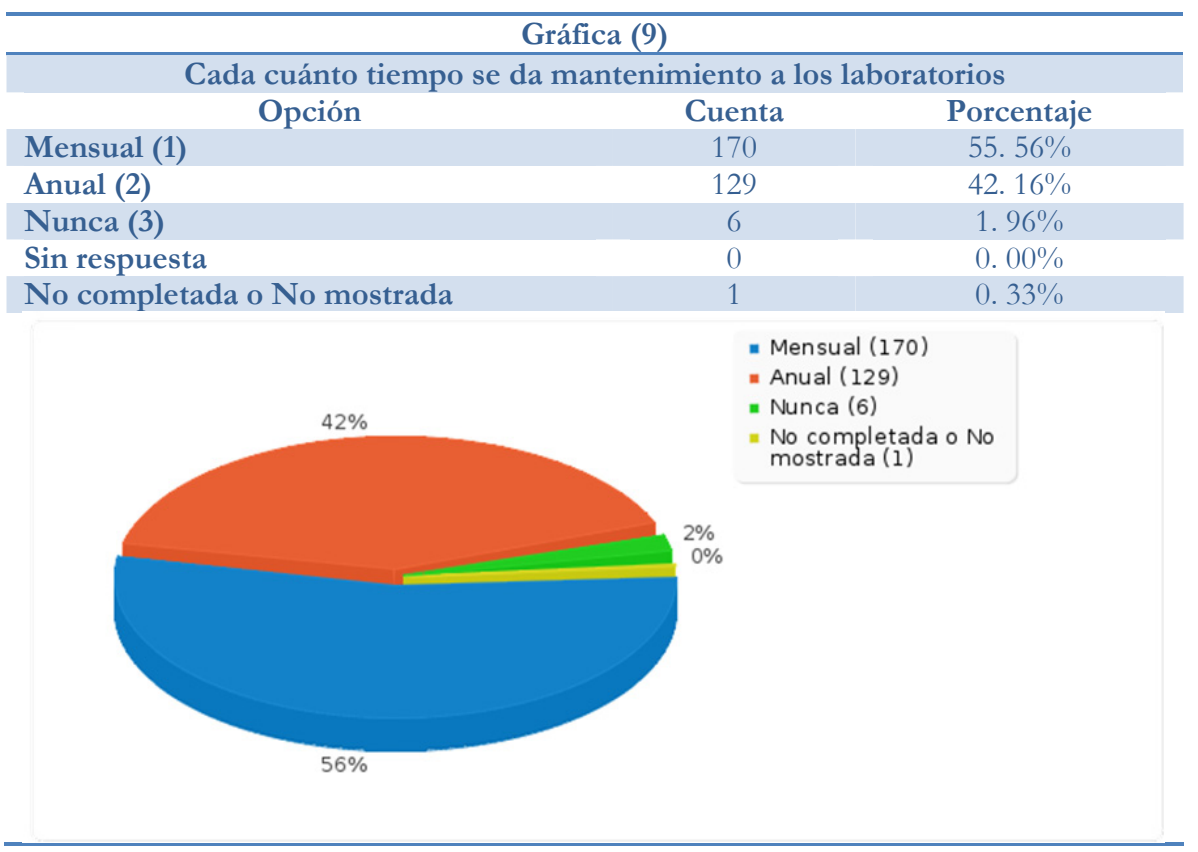

La colectividad escolar necesita estar conectada a una red integral. Una vez que lo logre, los educadores utilizarán los recursos, para acentuar los programas institucionales y lograr fines educativos específicos. Lograr resultados tan simples como demostrar la correspondencia entre tecnología y aprendizaje o de resultado tan extenso como el integrar el aprendizaje a una colectividad más extensa. Se halla una gran cantidad y diversidad de información útil en Internet. Llega de muchas formas: 
texto, imágenes, vídeo y sonido, documentos multimedia, programas, etc. Hay que tener precaución y no pensar que suministrar a los estudiantes información es lo mismo que facilitarles conocimientos. El conocimiento es consecuencia de la evolución individual de la información. El conocimiento es propio mientras que la información es pública. En consecuencia, es trascendental que en la "Era de la información", no sólo eduquen a tener acceso a la información sino, a manipular, examinar, criticar, comprobar, y convertirla en conocimiento positivo.

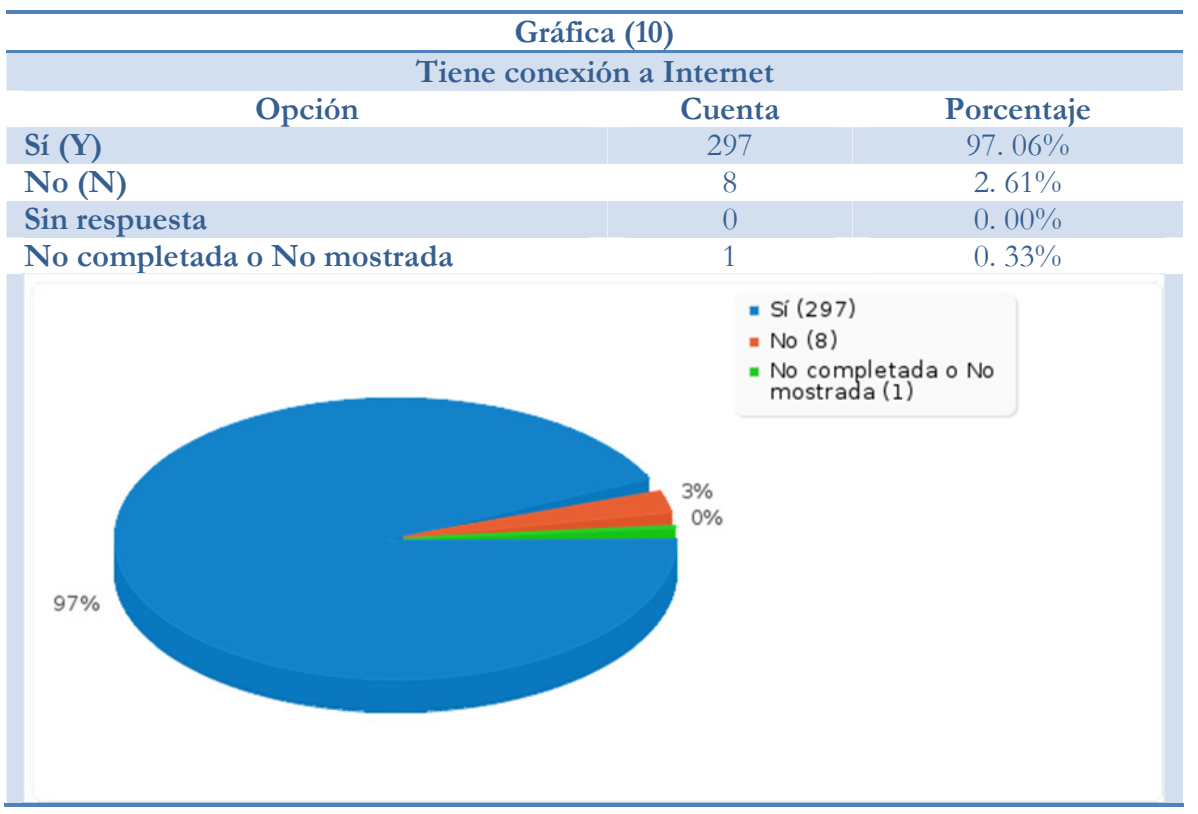

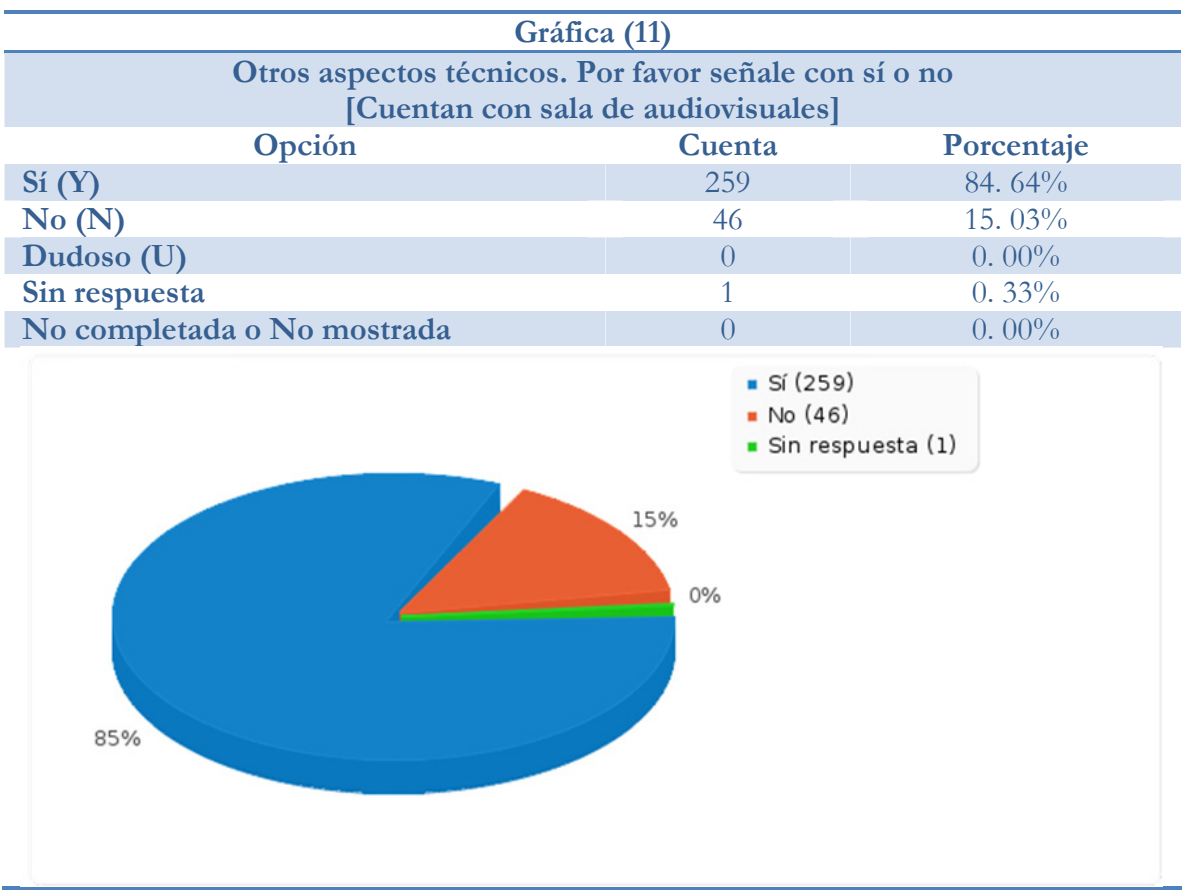




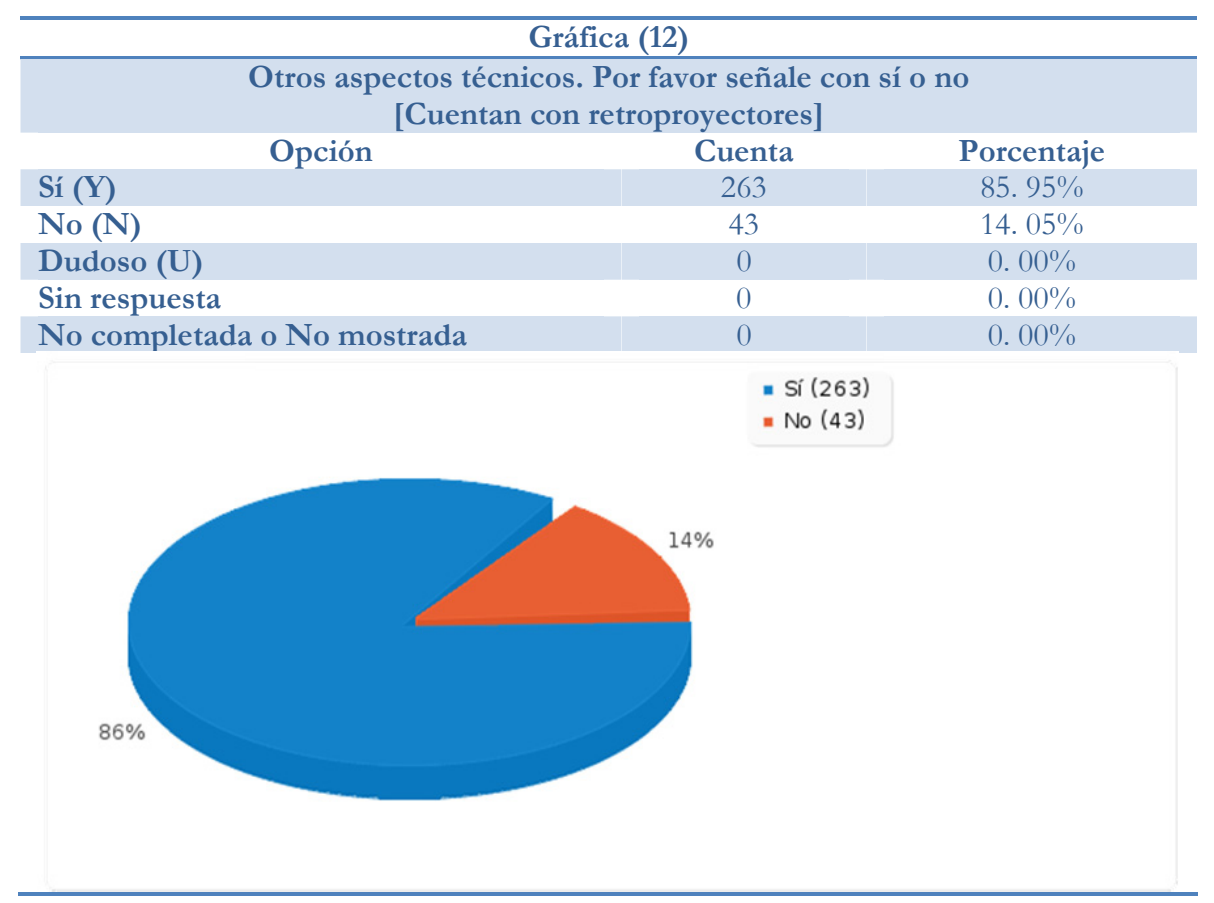

Las imágenes en los procesos de enseñanza - aprendizaje son muy significativas en muchos aspectos: a) suministran conocimiento, ya que, integran las explicaciones con elementos de fácil comprensión que afianzan los contenidos, b) son motivadoras y atraen el interés de los estudiantes hacia un tema establecido, c) facilitan las relaciones entre diferentes unidades y permiten examinar con detalle las diferentes fases de procesos confusos, d) pueden causar un golpe conmovedor en el alumno que genere emociones y cualidades propias, e) consiguen facilitar o extractar realidades ambiguas ( figuras, esquemas, gráficas, etc.) f) ayudan a conocer mejor el pasado (cuadros, estatuas, etc.) o ver realidades poco posibles (satélites, máquinas, etc.), g) mejoran el diálogo, ayudan a la evaluación y son un vehículo de recreación. 


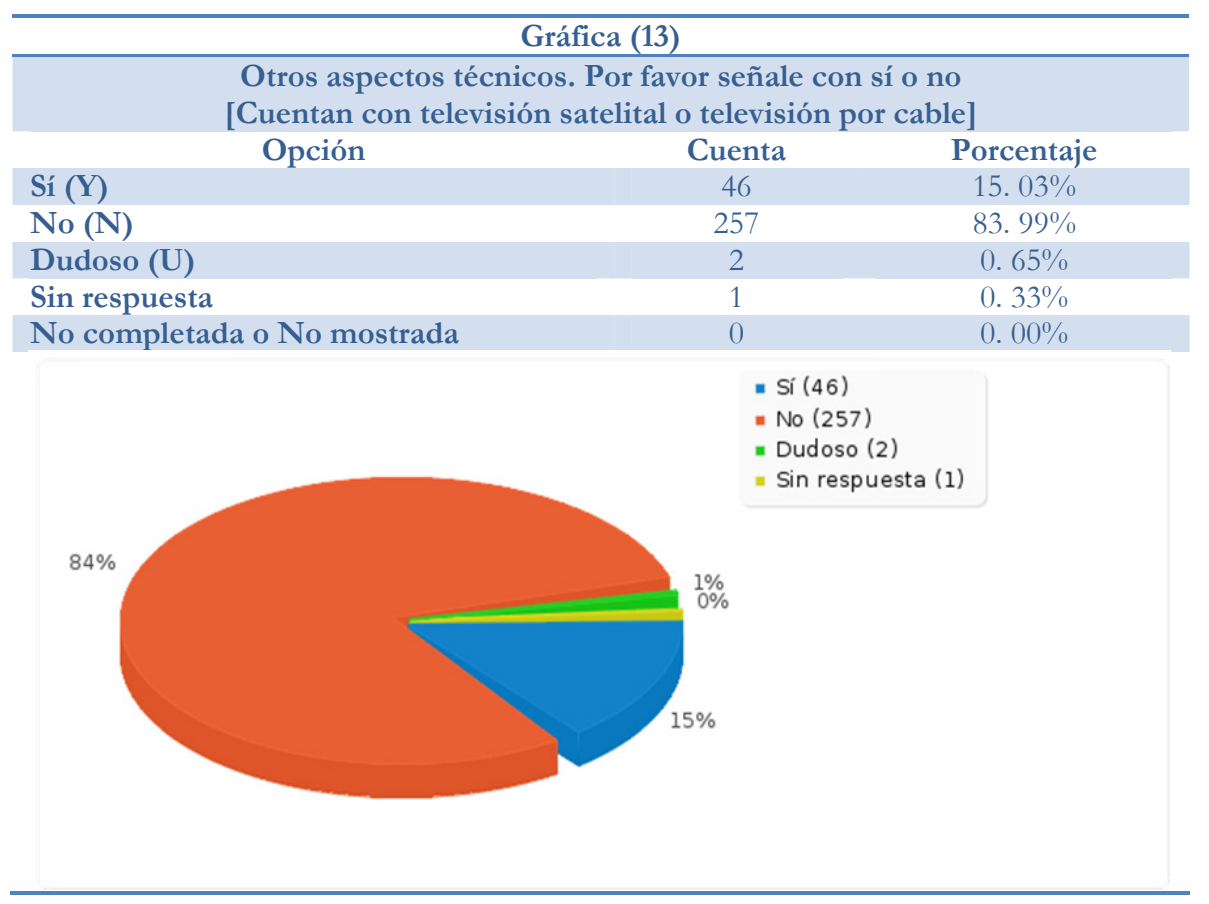

De todas las formas de comunicación actuales es sin duda la televisión el medio que tiene una presencia más amplia en la sociedad. La alianza de la imagen y el sonido y la posibilidad de su movimiento en el espacio, hace de ella una herramienta perfecta para superar ciertas barreras. Sus características comunicativas, radican en que la televisión nos permite una aproximación en el espacio y en el tiempo de contenidos a los que por otros medios sería muy complicado.

No obstante la televisión, como cualquier otro medio, agrega al proceso las condiciones propias de su particularidad comunicativa, lo que nos conduce a incorporar los mecanismos y habilidades adecuadas para su superación. 


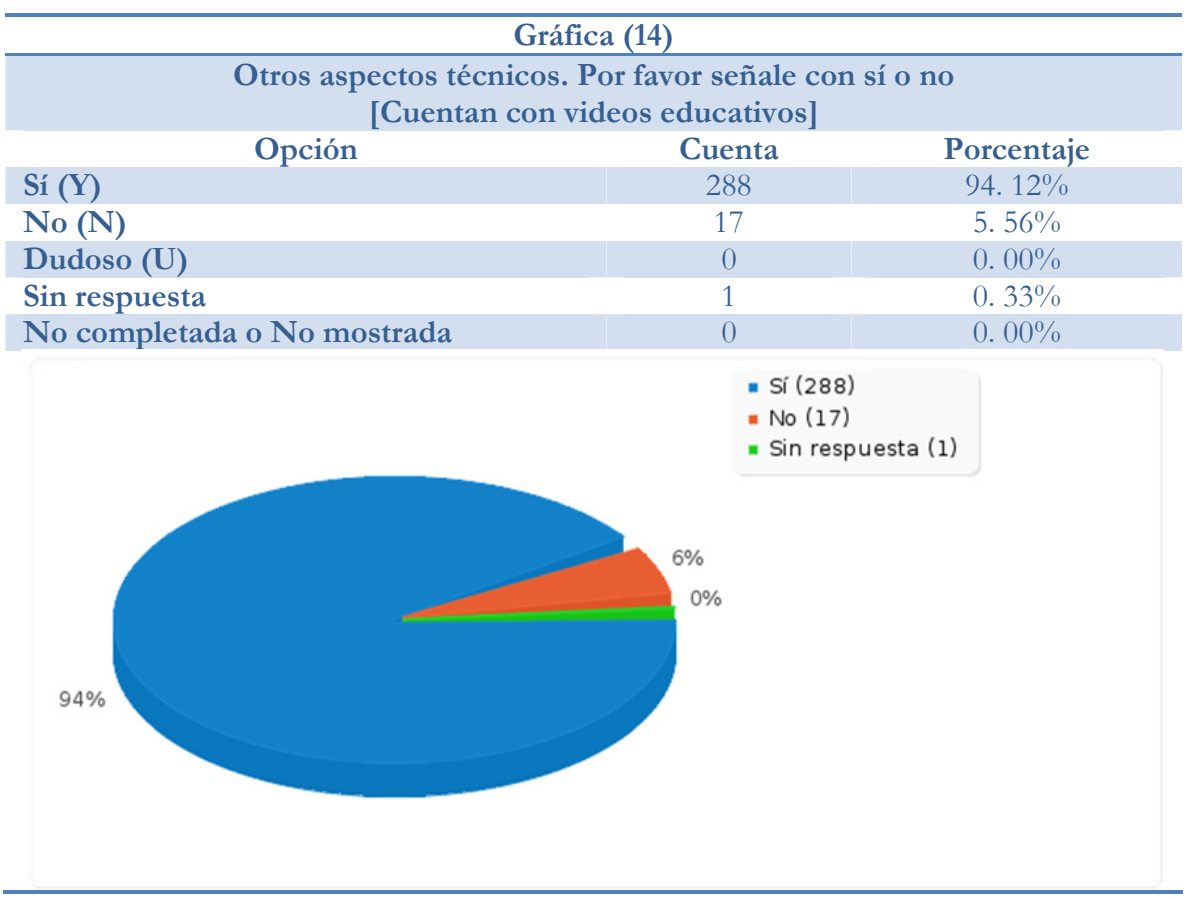

Entre los diversos recursos que se disponen, el video es un medio tecnológico que, por sus características expresivas, puede lograr un alto valor de motivación, lo que hace de él un instrumento de aprendizaje excelente para el alumno. Su uso puede ser encaminado desde distintos ámbitos: como complemento curricular, aprendizaje libre, educación a distancia y de circulación en general. Dentro de este entorno de aprendizaje, proporciona al alumno o al profesor la capacidad de inmovilizar la imagen, de retroceder y, en definitiva, adecuar el ritmo de visualización a los problemas de comprensión o retención que tenga y a las características propias del audiovisual. 


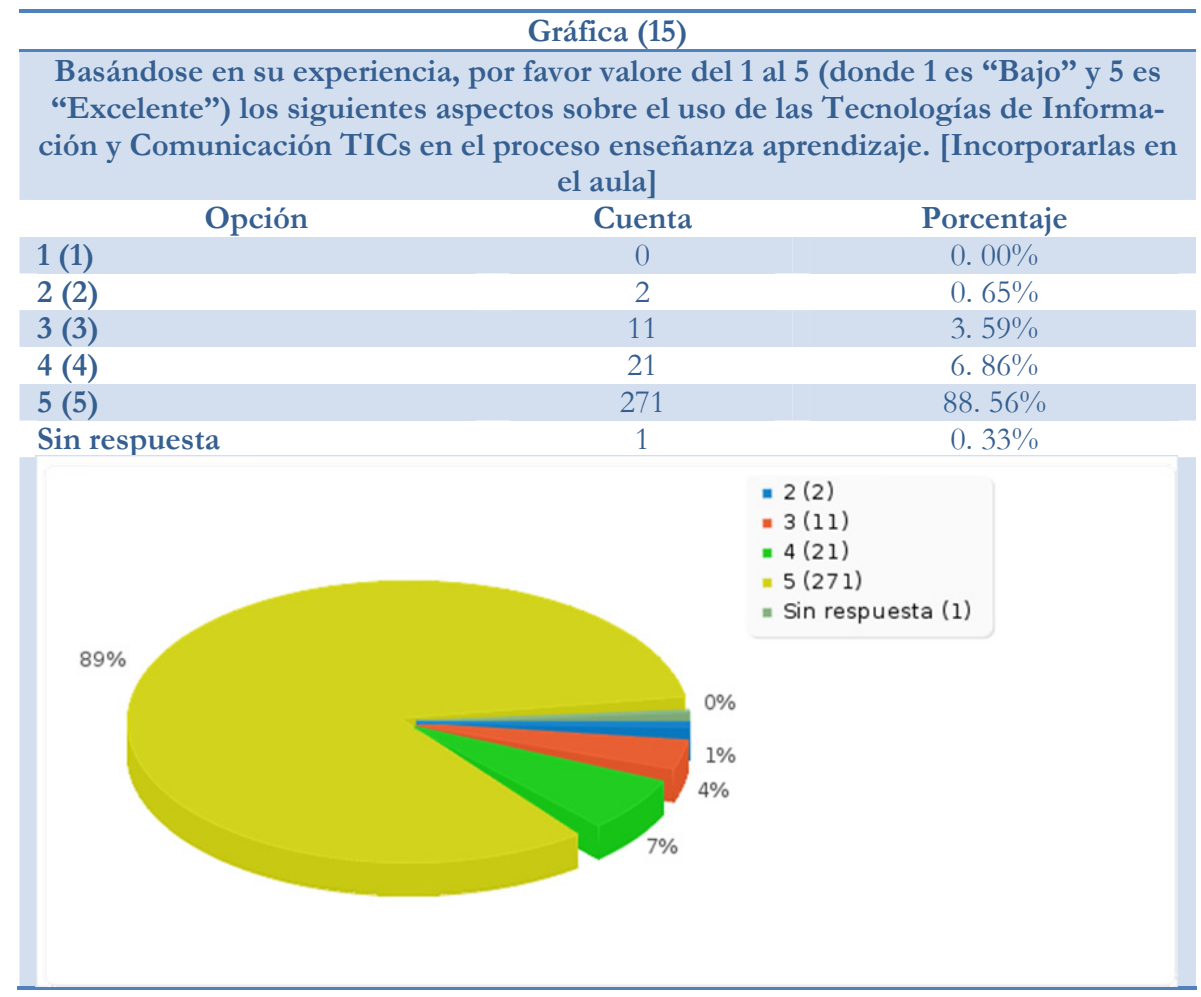

El docente actual debe tener una formación incesante, las instituciones educativas deben desenvolverse bajo un enfoque de alfabetización digital con servicios básicos y tecnológicos bien definidos, deben crear y aplicar nuevos procesos y nuevos espacios de formación para una diferente generación de alumnos. El manejo de las nuevas tecnologías en la clase involucra una serie de ideas y destrezas por parte de los docentes razón por la cual necesitan preparación no sólo en su uso, sino en la aplicación de nuevas habilidades de educación empleando las TICs. Por medio de ellas podremos acceder a bases de datos de diferentes tipos de contenidos y estructura, que van desde las que podríamos considerar como fuentes documentales de información, hasta las de explicación y ejercitación de los contenidos sobre los que los estudiantes pueden interactuar. 


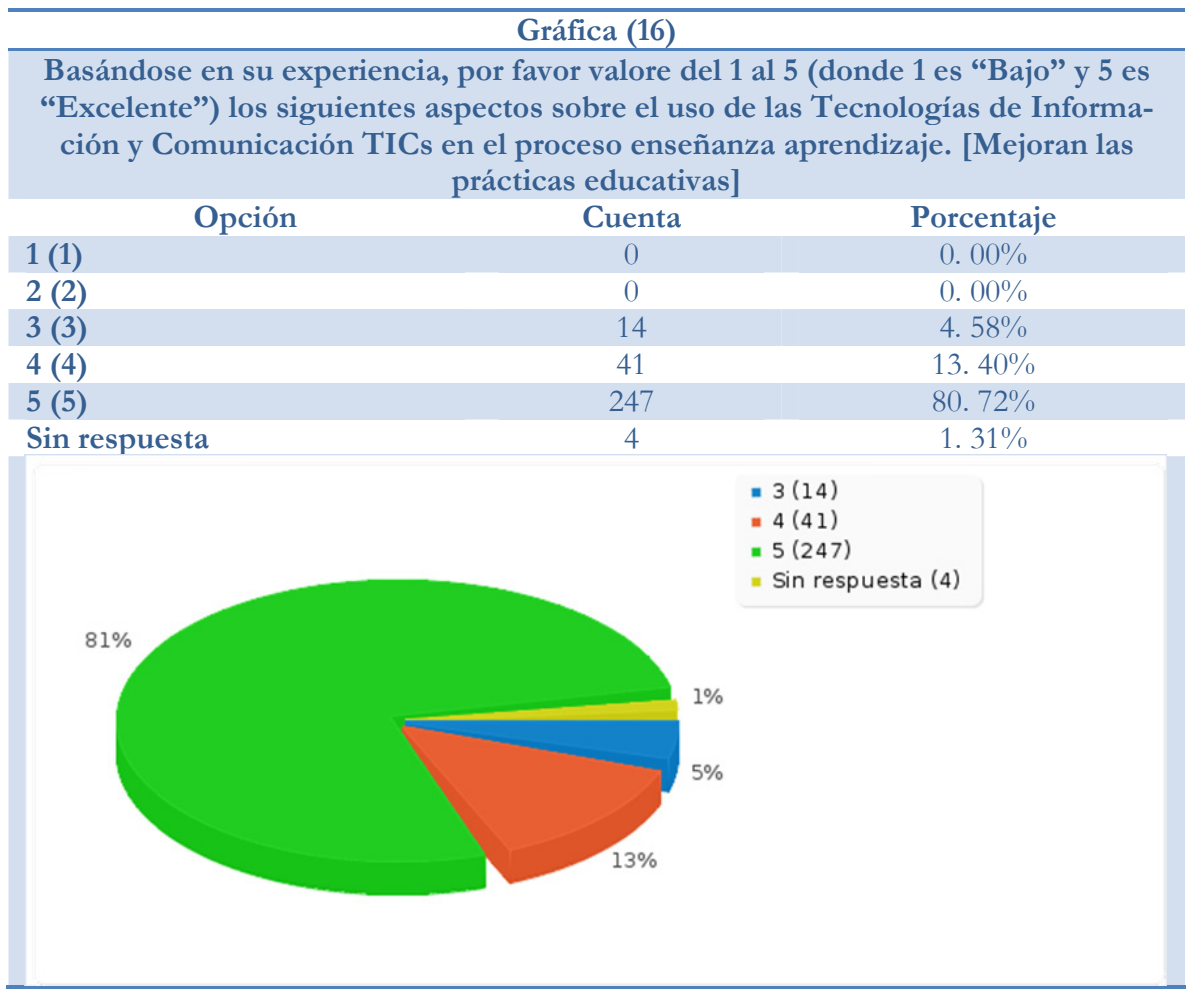

Las TICs permitirían empoderar a los recibidores en una medida que no era posible en los medios de comunicación clásicos. Especialmente importante sería la capacidad de convertir al tradicional receptor de un medio, en provisor de información para otros, y para el medio mismo.

Los estudiantes deben ser educados de una forma creativa, para poder exigir contenidos de calidad. Por otro lado, sería esperado eliminar el alejamiento de determinados segmentos de la población, que usualmente no encuentran contenido a su gusto en los medios de masas, como la televisión, la radio y la prensa, que están dirigidas a un público prototipo y mayoritario. 


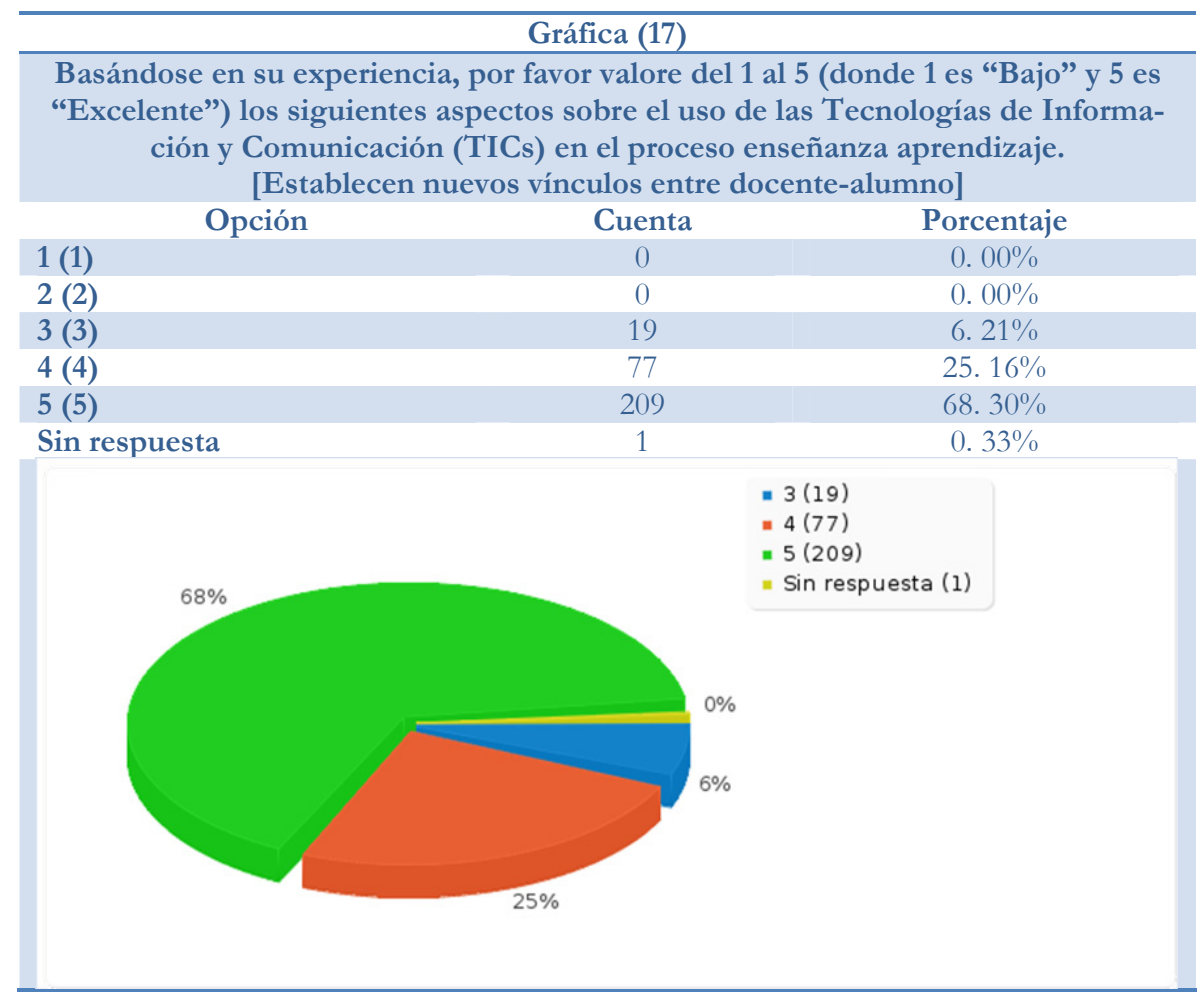

El nuevo modelo pedagógico para una educación atravesada por las TICs, no puede dejar de lado la consideración del rol docente, ya que estamos en presencia de un momento de evolución, donde debemos empezar a pensar y reflexionar el vínculo docente-alumno teniendo en cuenta la interacción entre el trato cara a cara en el mismo momento y el mismo lugar, y la particularidad asincrónica que supone la virtualidad. Tiempo y espacio varían, las relaciones entre docente-alumno también, así como las maneras de representar e idear el conocimiento. 


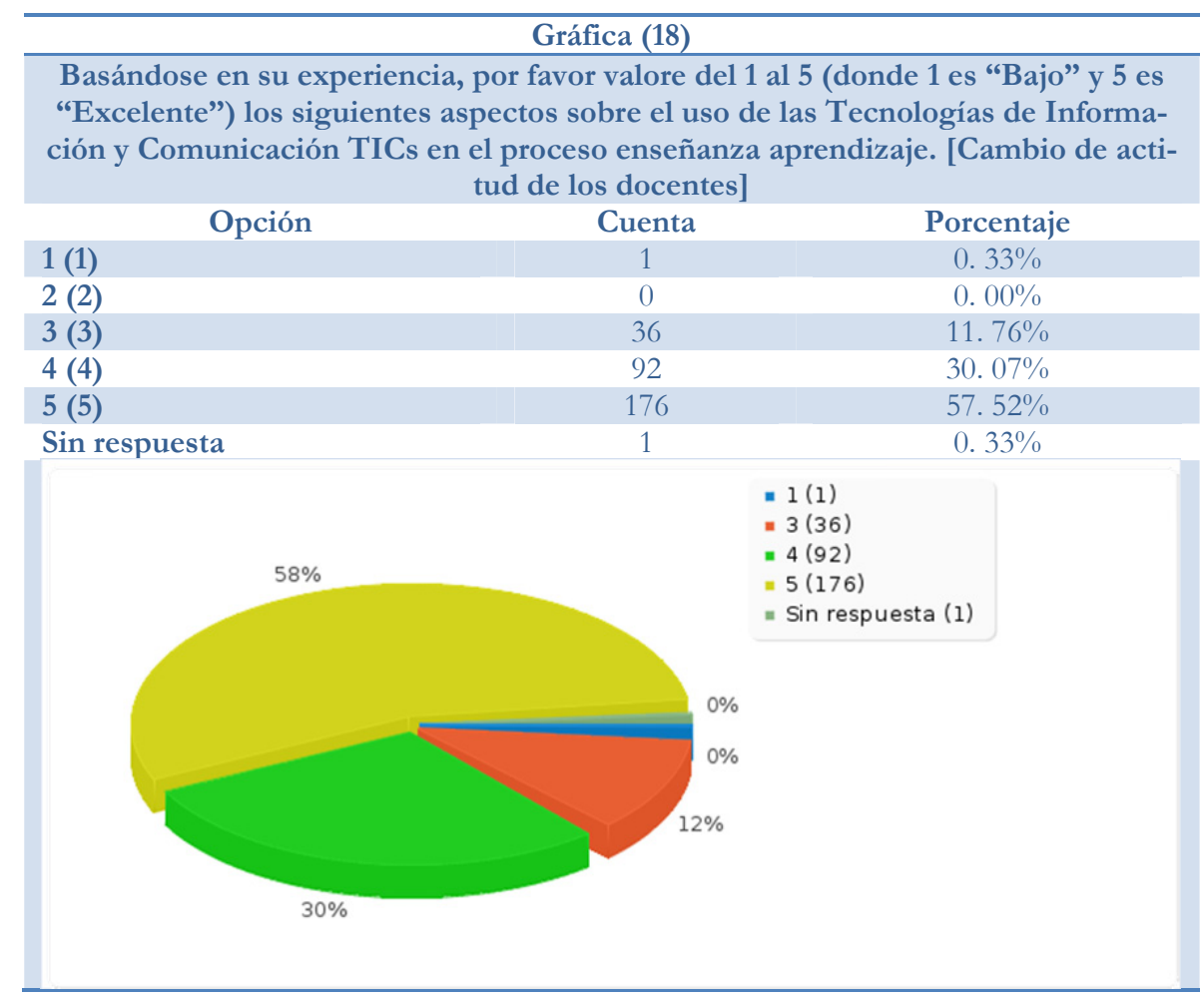

Si el profesor se muestra abierto a la posibilidad de usar las TICs para realizar cambios, y presto a investigar nuevos diseños de la enseñanza y el aprendizaje que puedan apoyarse en diferentes programas informáticos, si, y sólo si, se podrá promover un cambio.

Es necesario que los docentes tengan una actitud de cambio ante lo nuevo, que invariablemente gozará y aportará beneficios; cuando esto no está claro y solo se ve como más actividades; el objetivo de introducir alguna evolución o innovación, en este caso la tecnología; no tiene sentido, ya que solo involucra gastos y no un beneficio para lo que fueron diseñadas. 


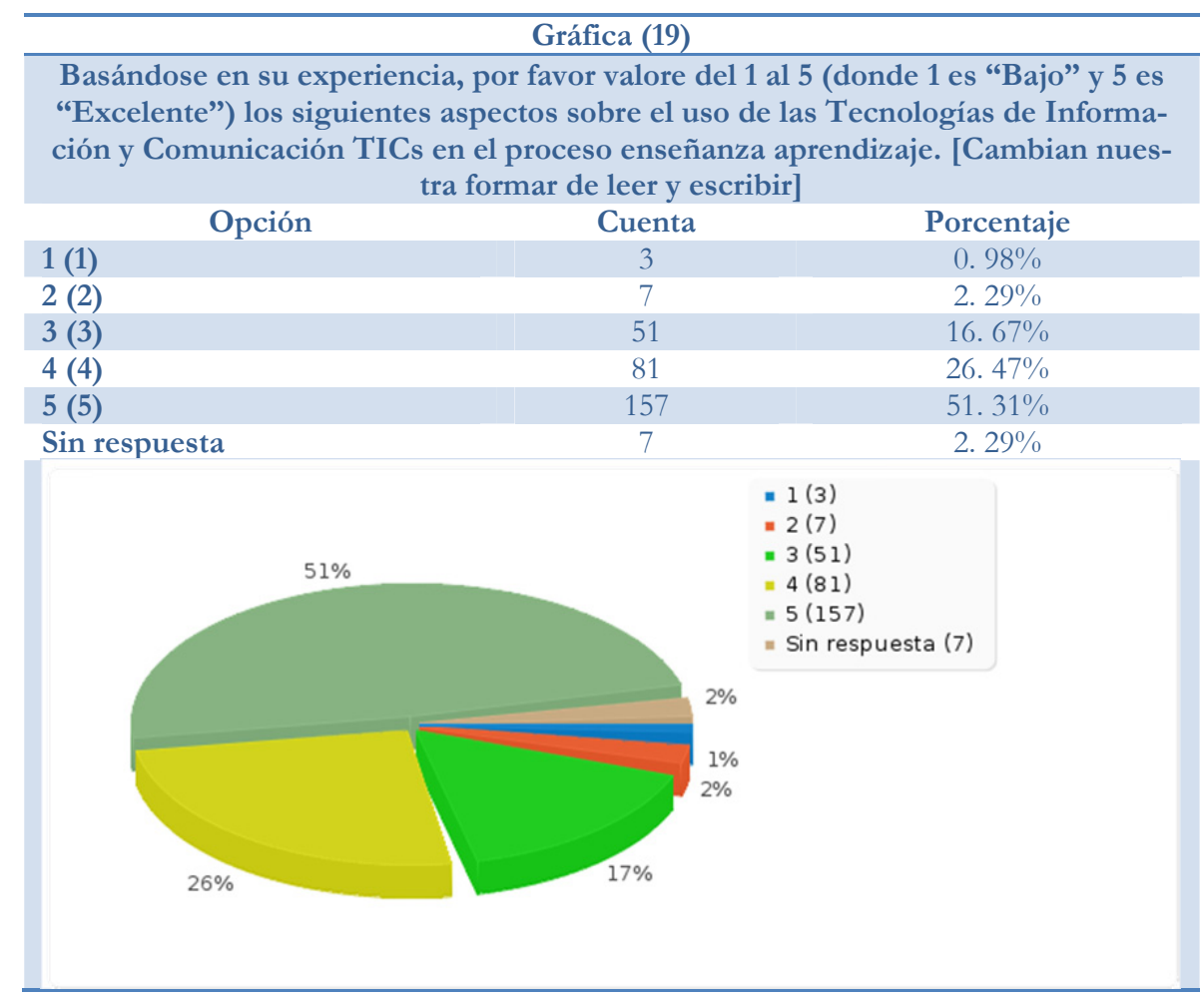

Pensando en la escritura de propiedad particular, el medio electrónico ayuda la divulgación ya que elimina intermediaciones propias de la edición impresa como correctores, editores, impresores, distribuidores, etc. La publicación electrónica permite la unión de todas esas funciones lo cual ha determinado que, lejos de inducir la desaparición de la escritura, la Red haya sido la fuente de estímulo a millones de personas a escribir y rápidamente publicar sus textos. La escritura como habilidad se extiende, frente al asombro de ciertos sectores que evidencian cómo la publicación digital promueve un hecho educativo novedoso de que "cualquiera puede escribir". 


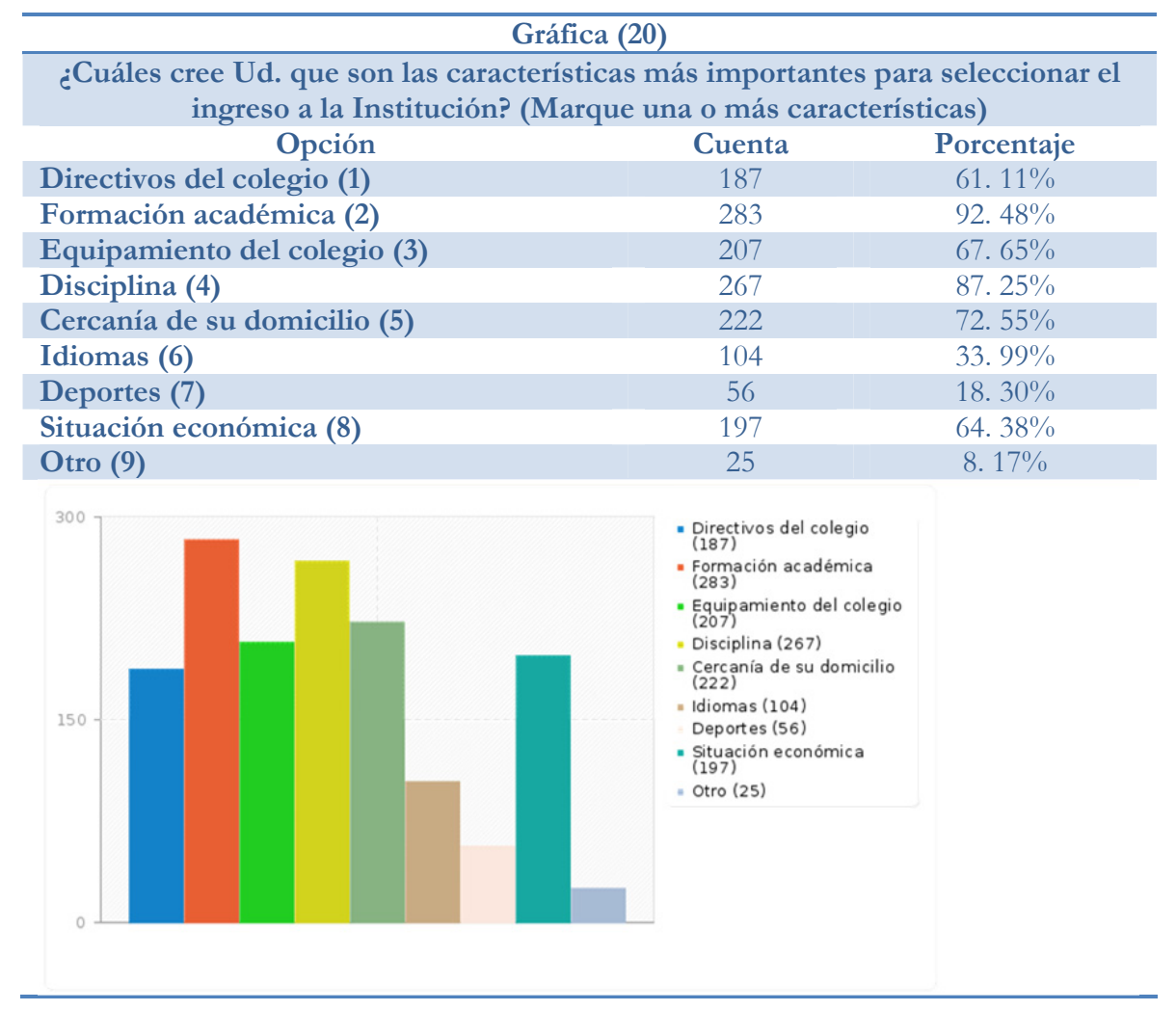

Gráfica (21)

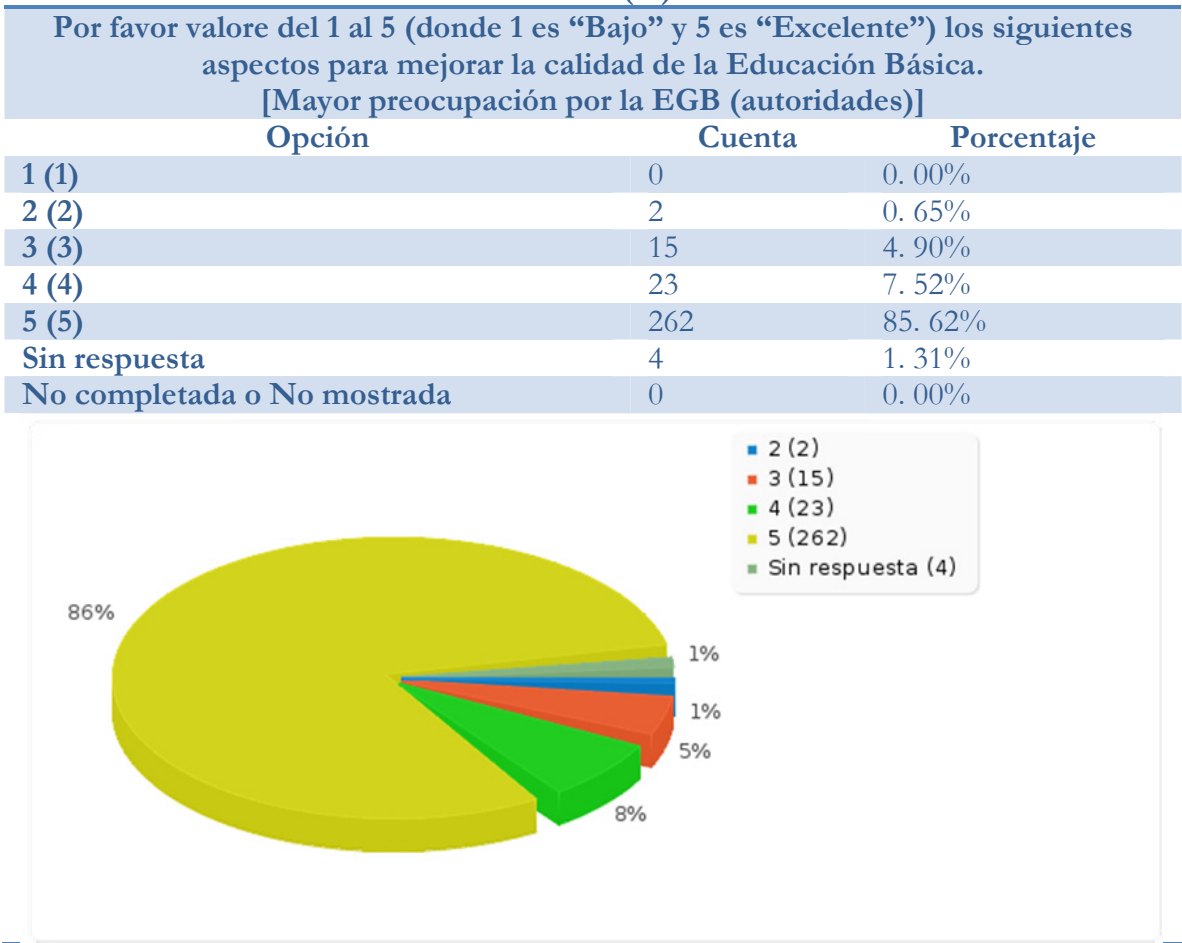




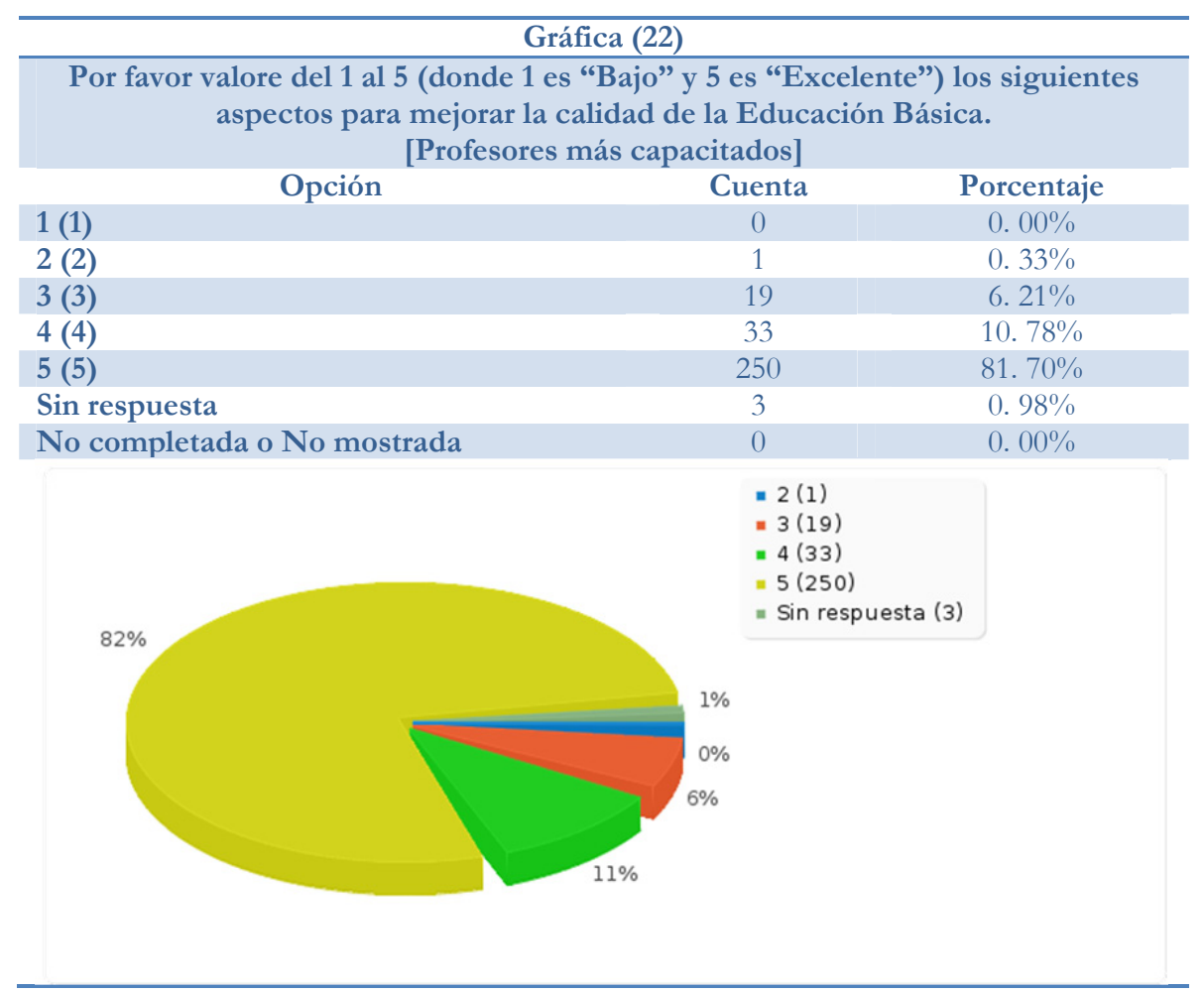

Es importante destacar el empeño y decisión de los diferentes actores de la sociedad en trabajar en forma coordinada una iniciativa país, así como la existencia de diversos empujes individuales que miran y topan la problemática desde su modo individual e institucional. Entre ellas se encuentran, por ejemplo:

Ministerio de Educación y la iniciativa Maestros, que proveerá a 10. 000 profesores un bono para la adquisición de un PC en el mercado y la capacitación de los docentes.

La Escuela Superior Politécnica del Litoral (ESPOL), el Gobierno de Pichincha y la

Fundación Ambientar, todos orientados a la formación de docentes.

Programa televisivo por Cable, EDUCAR, preocupado de la generación de contenidos de valor para los niños. 


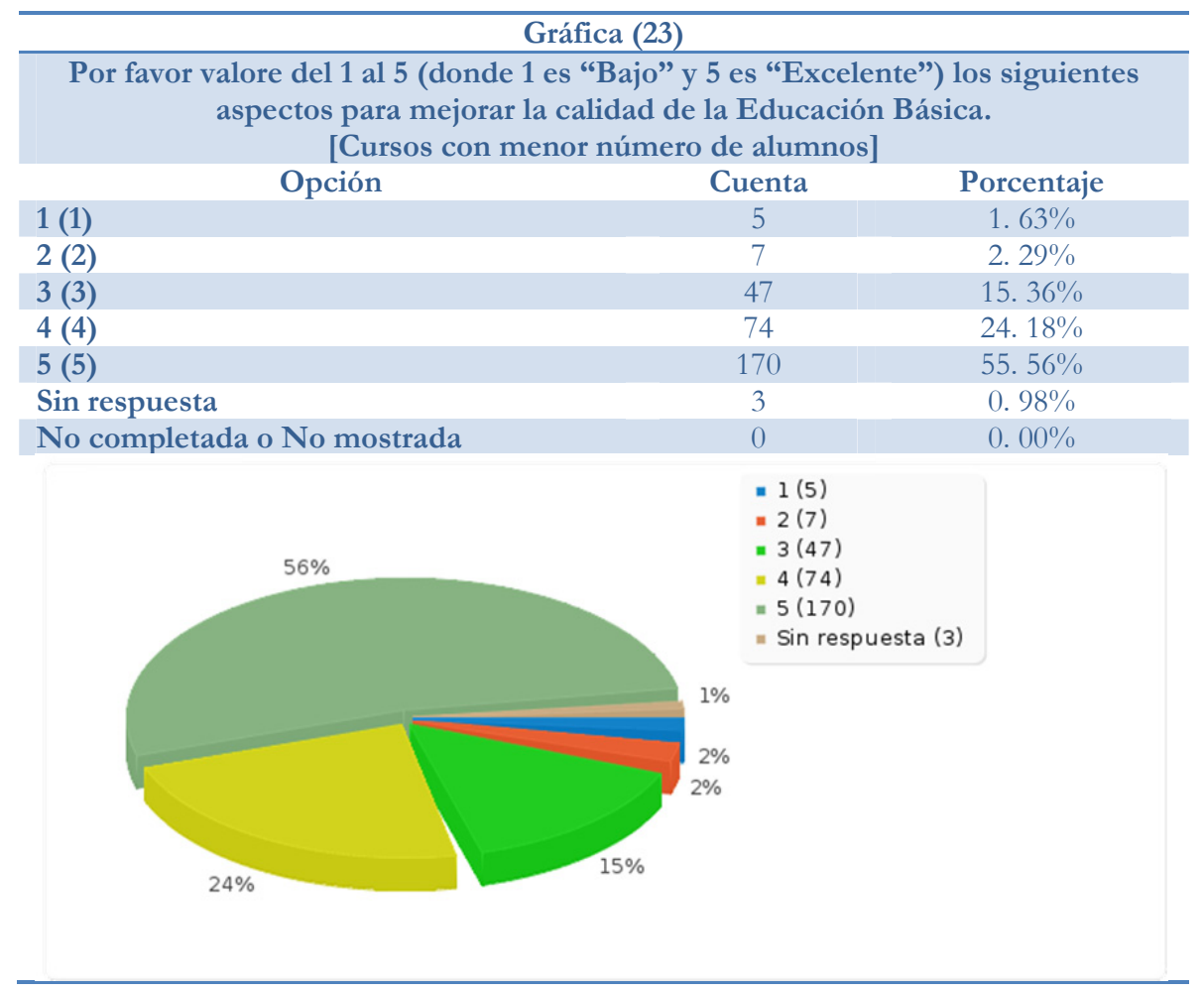

Teóricamente, en una clase con menos alumnos hay menos ruidos y menos factores distractores, y el profesor tiene más tiempo y más libertad para trabajar con el alumno, ayudándolo y estimulándolo a una mayor creatividad y participación.

En las escuelas chinas y japonesas, el promedio nacional es de 40 alumnos por sala, ellos aseguran que el rendimiento no depende en gran medida del número de alumnos, como de la calidad y entrega del profesor. Más aún, se resisten a proporcionar prácticas diferentes a distintos niños, ya que consideran que ello conduce a desigualdades que luego dificultan su competencia. 


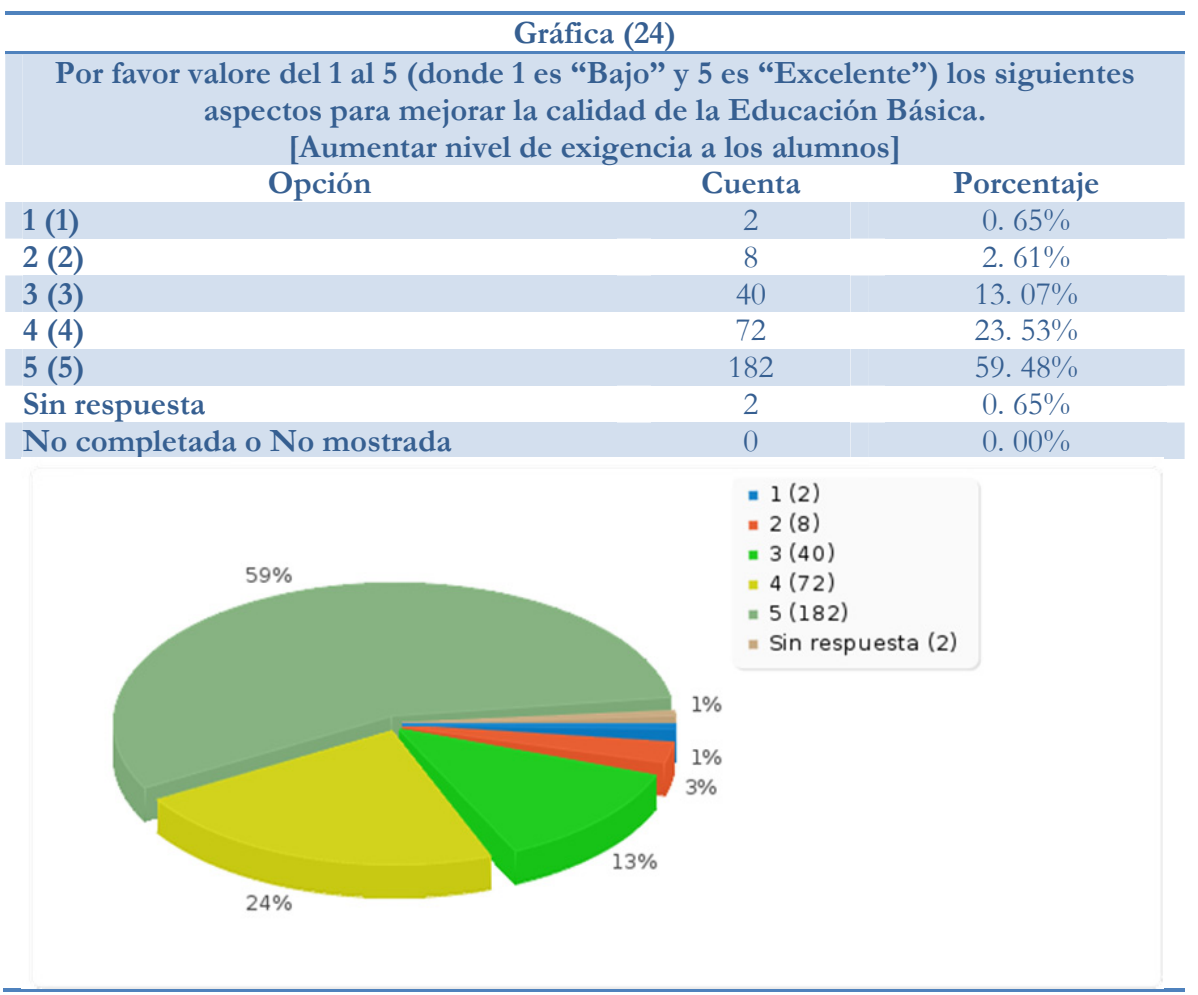

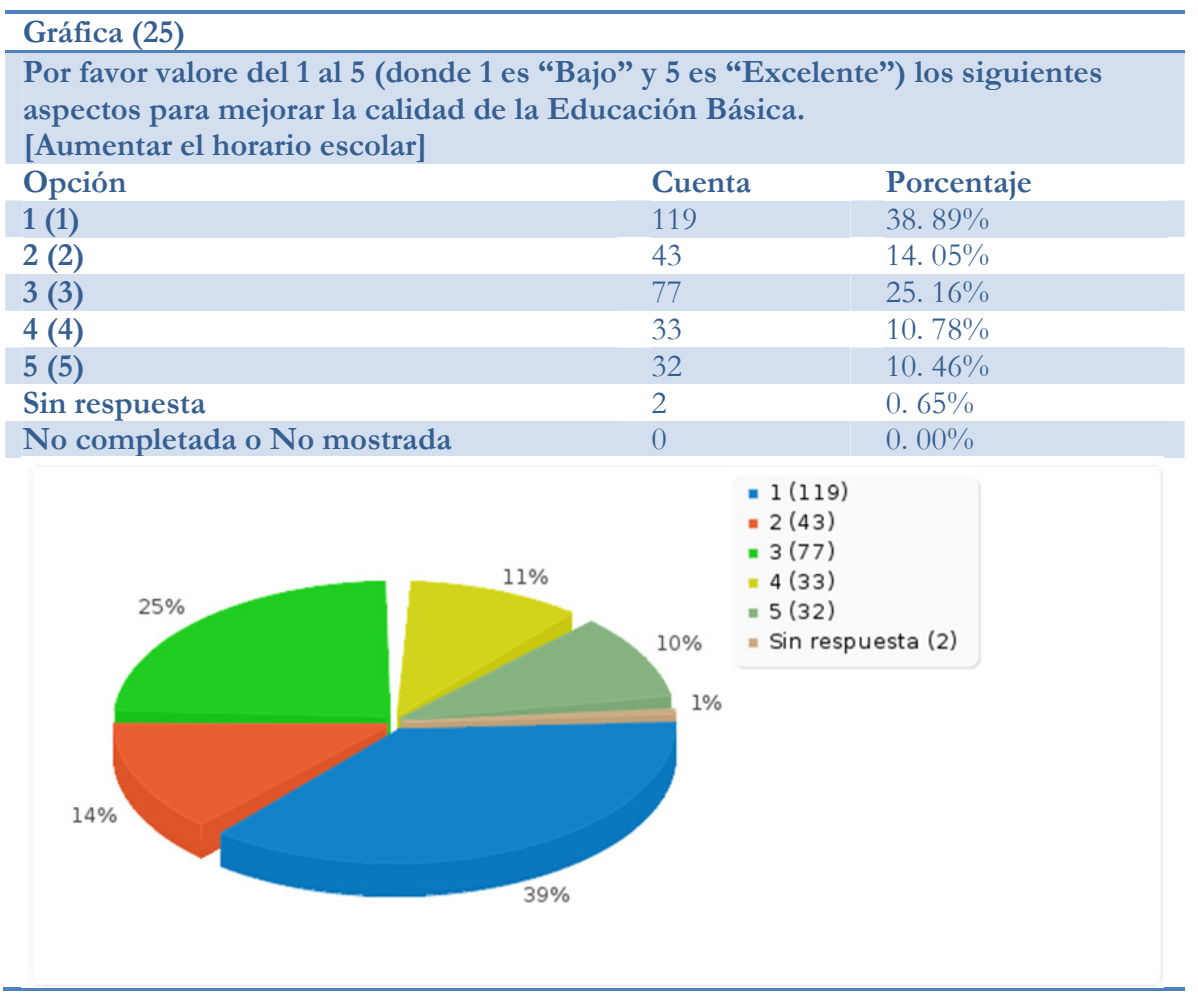


Un sobresaliente plan de estudios y los mejores y más avanzados materiales no resolverán por sí solos las dificultades de calidad y logros de los aprendizajes. Es, por lo tanto, en este punto donde el cambio de la educación tiene su mayor desafío: cambiar esencialmente la gestión y organización escolar, lo cual involucra a todo el personal docente, así como al personal no docente y de apoyo a la educación.

La formación de los maestros es un aspecto crucial para asegurar el establecimiento de un nuevo currículo, además crear nuevas maneras de trabajo en cada institución, se vaya consiguiendo con mayores certezas.

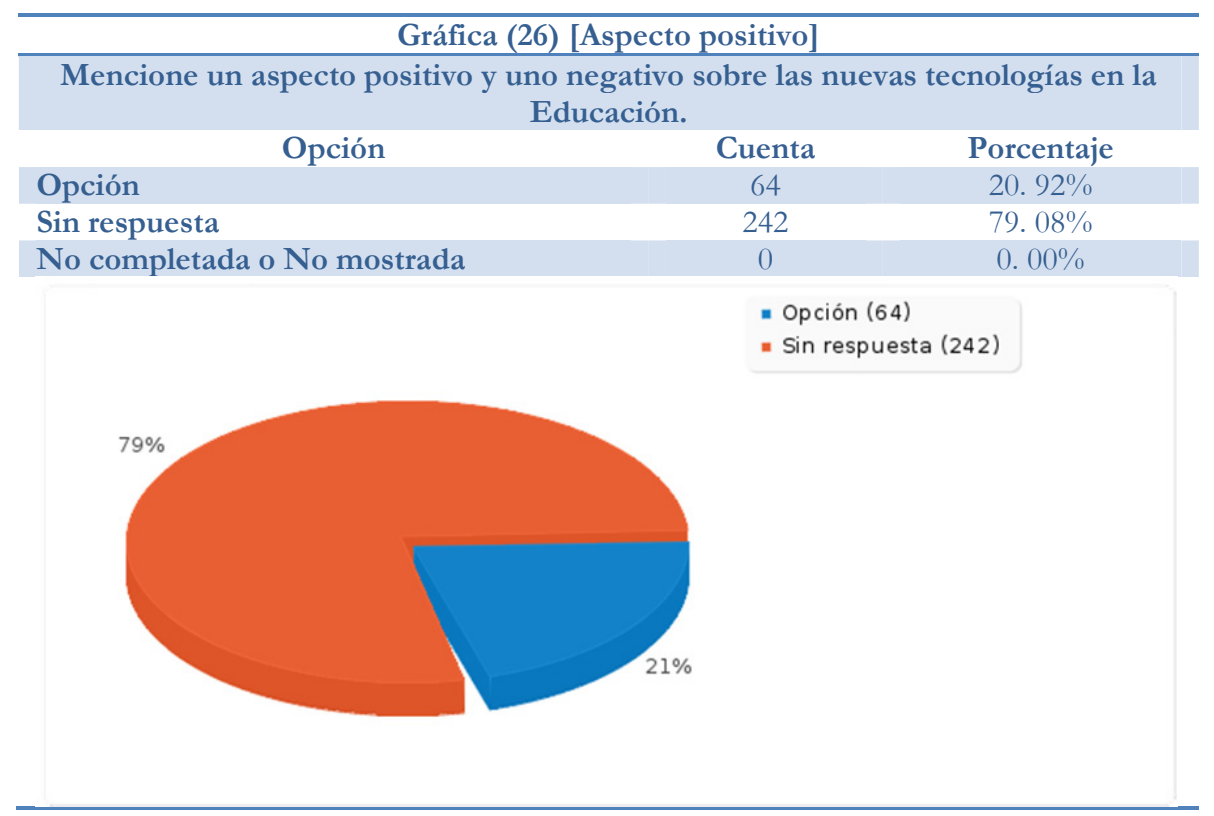

\section{Aspectos esperados:}

- Formación y actualización del docente en el uso de los medios didácticos y su adecuación a los distintos niveles educativos.

- Profundo conocimiento de los distintos recursos para su mejor aprovechamiento en las aulas.

- Interés por parte de los docentes por explorar las posibilidades que ofrece el empleo de los recursos en el aula.

- Dominio de estrategias de intervención en el manejo de materiales desde diseños que promuevan la creatividad, investigación y la autonomía de los alumnos.

- Conocer algunas razones de selección y evaluación de los diferentes recursos tecnológicos al servicio de la educación.

- Promover la alfabetización en las nuevas tecnologías para su aplicación con futuros alumnos. 
- Comprensión de aplicaciones de medios para las distintas áreas curriculares.

- Mayor tiempo y dedicación.

- Capacitación crítica.

- Manejo y uso frecuente de las herramientas tecnológicas desde planteamientos didácticos.

- Incentivar al alumno la producción de materiales.

Las tablas muestran los resultados por sostenimiento de la Institución: Fiscal y Particular.

\begin{tabular}{|c|c|c|c|c|}
\hline \multicolumn{5}{|l|}{ Tabla 5} \\
\hline & \multicolumn{2}{|c|}{ Fiscal } & \multicolumn{2}{|c|}{ Particular } \\
\hline \multicolumn{5}{|c|}{ Existen estudiantes con capacidades especiales } \\
\hline Si & 87 & $67,4 \%$ & 98 & $55,4 \%$ \\
\hline No & 42 & $32,6 \%$ & 79 & $44,6 \%$ \\
\hline \multicolumn{5}{|c|}{ Dispone de iluminación en las aulas } \\
\hline Si & 128 & $99,2 \%$ & 175 & $98,9 \%$ \\
\hline No & 1 & $0,8 \%$ & 2 & $1,1 \%$ \\
\hline \multicolumn{5}{|c|}{ Dispone de tomacorrientes } \\
\hline Si & 129 & $100,0 \%$ & 176 & $99,4 \%$ \\
\hline No & 0 & $0,0 \%$ & 1 & $0,6 \%$ \\
\hline \multicolumn{5}{|c|}{ Dispone de áreas recreativas } \\
\hline Si & 125 & $96,9 \%$ & 171 & $96,6 \%$ \\
\hline No & 4 & $3,1 \%$ & 6 & $3,4 \%$ \\
\hline \multicolumn{5}{|c|}{ ¿Cuentan con centros de cómputo o laboratorios? } \\
\hline Si & 128 & $99,2 \%$ & 177 & $100,0 \%$ \\
\hline No & 1 & $0,8 \%$ & 0 & $0,0 \%$ \\
\hline \multicolumn{5}{|c|}{ De cuántos laboratorios dispone } \\
\hline Uno & 16 & $12,4 \%$ & 24 & $13,6 \%$ \\
\hline Dos & 46 & $35,7 \%$ & 62 & $35,0 \%$ \\
\hline Tres o más & 67 & $51,9 \%$ & 91 & $51,4 \%$ \\
\hline \multicolumn{5}{|c|}{ Cada laboratorio dispone de cuántas computadoras } \\
\hline 1 a 5 & 3 & $2,3 \%$ & 2 & $1,1 \%$ \\
\hline 6 a 10 & 25 & $19,4 \%$ & 57 & $32,2 \%$ \\
\hline 11 o más & 101 & $78,3 \%$ & 118 & $66,7 \%$ \\
\hline \multicolumn{5}{|c|}{ En general cuál es el estado de las computadoras } \\
\hline Bueno & 57 & $44,2 \%$ & 124 & $70,1 \%$ \\
\hline Regular & 71 & $55,0 \%$ & 53 & $29,9 \%$ \\
\hline Malo & 1 & $0,8 \%$ & 0 & $0,0 \%$ \\
\hline \multicolumn{5}{|c|}{ Cada cuánto tiempo se da mantenimiento a los laboratorios } \\
\hline Mensual & 49 & $38,0 \%$ & 121 & $68,4 \%$ \\
\hline Anual & 75 & $58,1 \%$ & 54 & $30,5 \%$ \\
\hline Nunca & 5 & $3,9 \%$ & 2 & $1,1 \%$ \\
\hline \multicolumn{5}{|c|}{ Tiene conexión a Internet } \\
\hline Si & 124 & $96,1 \%$ & 173 & $97,7 \%$ \\
\hline No & 5 & $3,9 \%$ & 4 & $2,3 \%$ \\
\hline \multicolumn{5}{|c|}{ Cuentan con sala de audiovisuales } \\
\hline Si & 107 & $82,9 \%$ & 152 & $85,9 \%$ \\
\hline No & 22 & $17,1 \%$ & 25 & $14,1 \%$ \\
\hline \multicolumn{5}{|c|}{ Cuentan con retroproyectores } \\
\hline Si & 106 & $82,2 \%$ & 157 & $88,7 \%$ \\
\hline No & 23 & $17,8 \%$ & 20 & $11,3 \%$ \\
\hline Cuentan co & satel & o televis & able & \\
\hline
\end{tabular}


ING. JUAN CORONEL

\begin{tabular}{|c|c|c|c|c|}
\hline Si & 10 & $7,8 \%$ & 36 & $20,3 \%$ \\
\hline No & 119 & $92,2 \%$ & 141 & $79,7 \%$ \\
\hline \multicolumn{5}{|c|}{ Cuentan con videos educativos } \\
\hline $\mathrm{Si}$ & 119 & $92,2 \%$ & 169 & $95,5 \%$ \\
\hline No & 10 & $7,8 \%$ & 8 & $4,5 \%$ \\
\hline \multicolumn{5}{|c|}{ Disponen de computadoras portátiles } \\
\hline Si & 45 & $34,9 \%$ & 61 & $34,5 \%$ \\
\hline No & 84 & $65,1 \%$ & 116 & $65,5 \%$ \\
\hline
\end{tabular}

Tabla 6. - Basándose en su experiencia, por favor valore del 1 al 5 (donde 1 es "Bajo" y 5 es "Excelente") los siguientes aspectos sobre el uso de las Tecnologías de Información y Comunicación Tics en el proceso enseñanza aprendizaje.

\begin{tabular}{l|cc}
\hline \multicolumn{1}{c}{ Aspecto } & \multicolumn{2}{c}{ Promedio } \\
& Fiscal & Particular \\
\hline Incorporarlas en el aula & 4,8 & 4,8 \\
Mejoran las prácticas educativas & 4,8 & 4,8 \\
\hline Establecen nuevos vínculos entre docente-alumno & 4,6 & 4,6 \\
Enemigas de los libros & 3,9 & 3,9 \\
Cambio de actitud de los docentes & 4,5 & 4,4 \\
Cambian nuestra formar de leer y escribir & 4,3 & 4,3 \\
\hline
\end{tabular}

Tabla 7. - Por favor valore del 1 al 5 (donde 1 es "Bajo" y 5 es "Excelente") los siguientes aspectos para mejorar la calidad de la Educación Básica.

\begin{tabular}{lcc}
\multicolumn{1}{c}{ Aspecto } & \multicolumn{2}{c}{ Promedio } \\
& Fiscal & Particular \\
Mayor preocupación por la EGB (Autoridades) & 4,7 & 4,9 \\
\hline Profesores más capacitados & 4,7 & 4,8 \\
Mejorar remuneraciones profesores & 4,6 & 4,7 \\
\hline Cursos con menor número de alumnos & 4,4 & 4,3 \\
Aumentar nivel de exigencia a los alumnos & 4,3 & 4,4 \\
Mayor cantidad de equipamiento & 4,5 & 4,6 \\
Mejores textos de estudio & 4,3 & 4,3 \\
Aumentar el horario escolar & 2,4 & 2,4 \\
\hline
\end{tabular}

\section{DISCUSIÓN}

\section{IMPACTO EN LOS MAESTROS Y EN LA ENSEÑANZA}

- Una gran mayoría de los maestros utilizan las TIC para preparar sus clases.

- Los docentes utilizan las TIC para planear sus clases de manera más eficaz y segura. Las TIC les viabilizan una mayor colaboración y comunicar planes curriculares con colegas y directivos.

- El uso positivo de la Información llevan al aumento formal de la cooperación entre maestros, cosa que tiene un impacto significativo en las prácticas de enseñanza. A pesar de aquello, no hay una visión positiva sobre el uso con fines pedagógicos. 
- Tener un acceso ordenado a la exploración en Internet desarrolla en los estudiantes destrezas de búsqueda e investigación, que pueden trasladarse a través del currículo.

- Las salas de audiovisuales, la televisión, los videos, marcan una diferencia en la interacción en las aulas.

- Las mediaciones del estado han impactado la enseñanza de las TIC y han llevado a un uso "más constante" de las TIC integradas en procesos de aula.

- Se utiliza las TIC para apoyar las prácticas educativas existentes. Las TIC se utilizan más cuando se ajustan mejor a las experiencias cotidianos.

- El mayor interés se encuentra entre los maestros que son usuarios habituados y que desde el inicio han avanzado mucho en la integración de las TIC en sus técnicas de enseñanza.

- El impacto de una herramienta específica o de un dispositivo de las TIC, estriba en la capacidad del maestro para extraerles la mejor utilidad con fines pedagógicos. Factores que no puede controlar el maestro influencian la adopción de las TIC, por ejemplo: cultura institucional, liderazgo, currículo y evaluaciones.

- Las TIC pueden perfeccionar la enseñanza mejorando lo que ya está en práctica o, encajando nuevas y mejores maneras de aprender y de enseñar.

- Los docentes todavía no han conseguido aprovecharse del potencial creativo de las TIC ni han involucrado a los estudiantes más enérgicamente en la generación de conocimiento.

\section{BARRERAS}

- Maestros: La ausencia de competencia de los docentes en el uso de las TIC, la baja estimulación y la falta de seguridad en el uso de nuevas tecnologías en la enseñanza, son razones importantes de sus niveles de compromiso con las TIC; están relacionadas con los programas de capacitación de maestros.

- Instituciones: La poca o ninguna importancia dentro de las estrategias generales de la institución y la experiencia limitada con actividades encaminadas a planes apoyados por las TIC.

\section{INTERROGANTES}

Para aquellos promovedores de las TIC, que han realizado inversiones en ellas y las han implementado, es importante contar con una demostración firme de que las inversiones tienen una correlación clara con los resultados; pero nacen varias interrogaciones:

- ¿Qué acciones se podrían realizar para mejorar los rendimientos en matemáticas y en otras asignaturas para poder llevarlas a los niveles deseables? 
- ¿Necesitamos mostrar a los maestros más estrategias para utilizar también las TIC en otras asignaturas?

- La práctica profesional de los maestros no cambia mucho cuando utilizan las TIC. ¿Es esto conveniente? ¿Qué ocurre cuando un estudiante con destreza y confianza en las TIC fracasa por estudiar en una institución sin experiencia e inmadura en este aspecto?

- Podemos establecer algunas preguntas provocadoras que van más allá de la evidencia y son las siguientes: ¿Son los resultados tan buenos? ¿Cuál debería ser el nivel óptimo de las TIC? o ¿Existe un punto de comparación? La evidencia no muestra grandes logros principalmente en lo relativo al beneficio y mejora institucional. ¿Se ha logrado lo suficiente? De no ser así, ¿es posible renovar la enseñanza para aprovechar de mejor manera las TIC? ¿Cuáles son los círculos de enseñanza óptimos para que las inversiones en TIC den buenos resultados?

- ¿Están los investigadores en el camino correcto? o ¿los organismos comprometidos de formular las políticas públicas son claras y objetivas acerca de los resultados que esperan de las inversiones en TIC?

- ¿Cómo podemos relacionar los resultados específicos de una ciudad con las políticas nacionales de esta sobre TIC?

- Los plazos para el cambio educativo son largos. ¿Cómo podemos acelerar los procesos de cambio en las escuelas?

\section{RECOMENDACIONES}

\section{POLÍTICAS}

\section{Innovación}

Impulsar el proceso de innovación y dirección del cambio, para los cuales las TIC son el vehículo de socialización. Si el contexto organizacional e institucional no apoya nuevas formas de trabajo, las prácticas educativas no cambiarán. Partiendo de que la mayoría de los maestros acepta las nuevas tecnologías en un proceso paso a paso, en forma metódica pero lenta, cualquier cambio es necesario complementar con la administración de los procesos y debe estar acoplado a enfoques realistas. Es decir, dar a las escuelas libertad de experimentar dentro de ciertos términos.

\section{Incorporación}

En muchos estudios se muestran que las TIC impactan el desarrollo de capacidades, trabajo en conjunto, aprendizaje autónomo y habilidades de pensamiento crítico, pero esto aún no lo reconocen muchos sistemas educativos. Estas capacidades deberían ser incluidas formalmente en los currículos 
y hay que analizar las formas de evaluarlas. Estas son consecuencias significativas de un entorno educativo nuevo y diferente.

\section{Incentivar}

La capacitación de los maestros debería estar más relacionada con el concepto de aprendizaje a largo plazo, conocimiento colaborativo y aprendizaje entre colegas. Para consolidar la seguridad en ellos mismos, los docentes deben poder mejorar sus habilidades en el manejo de las TIC y extender sus conocimientos pedagógicos en forma mucho más dinámica de lo que lo hacían anteriormente. Los eventos de capacitación deberían llevarse a cabo en la escuela y adecuarse a las necesidades propias de los maestros, de las asignaturas o de los proyectos. El desarrollo profesional permanente tiene que ser prioritario para asegurar que los maestros puedan mejorar sus competencias.

\section{Recompensar.}

Conjuntamente con el acceso a la infraestructura y al contenido, y tener las habilidades requeridas, la motivación de los maestros es un factor muy importante en la aceptación de las TIC. Las políticas en este sentido deberían incluir disposiciones que aumenten el grado de confianza de los maestros (suficiente apoyo en el sitio de trabajo y capacitación tanto para los docentes en práctica como en la formación inicial). Es necesario que se incentive, reconozca y recompense el uso de las TIC.

\section{ESCUELAS}

\section{Investigación}

En áreas tan delicadas como la educación y la pedagogía, son imperiosos métodos cuantitativos para investigar los impactos. Se debe ir más allá de las observaciones y evaluar en forma más específica el entorno de la escuela, los ambientes en que se instruye y los pasos en que se enseña, para descubrir bajo qué circunstancias las actividades basadas en las TIC pueden mejorar el aprendizaje. Lo que necesitan saber los responsables de construir las políticas es qué funciona, para quién y en qué casos.

\section{Práctica}

Hay que armonizar la investigación básica, orientada hacia herramientas específicas de las TIC, con otra investigación más estrechamente relacionada a la práctica: también se puede, desarrollar una actitud reflexiva entre los docentes o que ellos investiguen por sí mismos e incluir a las escuelas en la propuesta de las preguntas de la investigación. Más aún, debería ponerse a disposición de los involucrados los resultados de la investigación en forma tal que les resulte útil. 


\section{Decisiones}

Revisar de forma general los diferentes puntos de vista de investigaciones ya realizadas en ese campo, puede servir a quienes construyen las políticas a decidir sobre el enfoque nacional que mejor se acople a sus objetivos y a su contexto educativo. No obstante, los creadores de políticas deben pensar en: medir el alcance y progreso en habilidades básicas por parte de los estudiantes, pero así mismo, esto implica asumir un sistema educativo establecido en el cual el aprendizaje se refiere primordialmente al dominio de un conjunto específico de conocimientos, habilidades y juicios.

\section{CONCLUSIONES}

\section{Basada en de Investigación}

Evaluar los cambios en los procesos de educativos es una tarea que requiere tiempo, pero que pueden producir consecuencias valiosas. Conocer cómo la tecnología educativa genera cambios en las prácticas de enseñanza, es fundamental para evaluar su validez y para el desarrollo de mejores herramientas. La valoración del impacto de las decisiones del gobierno es crucial para tomar decisiones informadas sobre la conveniencia de ampliar o modificar una política o programa en particular y desarrollar acciones futuras.

\section{Resultados del aprendizaje}

En los estudios revisados se han identificado una serie de importantes beneficios de las TIC en el aprendizaje. Estos incluyen el impacto positivo de las TIC en la motivación de los estudiantes y competencias, el aprendizaje personal y el trabajo en grupo. Los estudios muestran que estos beneficios no sólo pueden ser impulsados por la tecnología, sino que, deberían estar ligadas intencionalmente con un enfoque pedagógico.

En general, la base de pruebas (reales y percibidas) muestra que las TIC tienen un efecto positivo en los niveles de rendimiento relacionados con tema.

\section{Metodologías de la enseñanza}

Podemos asumir que las escuelas son el comienzo de la segunda etapa hacia la evolución de un nuevo paradigma educativo. Actualmente, las TIC han tenido un efecto sobre algunos profesores, pero no ha logrado cumplir su propósito a una escala mayor. Por lo tanto, los resultados serán visibles sólo en los próximos años. 
Las razones por las que predominan los enfoques tradicionales se encuentran en el limitado impacto de los programas de formación, así como de las barreras externas, tales como el currículo, la organización creada en las escuelas y en la dirigencia.

La disponibilidad de la tecnología por sí sola no es el único factor para la integración exitosa de las TIC, pero su ausencia o mala calidad debido a la insuficiencia de mantenimiento es un obstáculo crucial.

La falta de conocimientos en TIC de los profesores y la actualización de estas habilidades sigue siendo una barrera importante, ya que influye en la elección de maestros con formación en TIC. Esto, por otra parte influye en la capacidad de los profesores a adoptar nuevas prácticas pedagógicas.

Los sistemas de TIC aplicados durante un largo periodo de tiempo han dado lugar a un mayor uso de las TIC por parte profesores y aumentar considerablemente la confianza en el uso de las mismas.

\section{BIBLIOGRAFÍA}

ÁREA MOREIRA, Manuel, Los medios y las tecnologías en la educación, Madrid, Ediciones Pirámide, 2004.

Barbara Schroder, Developing Intercultural Science Education in Ecuador, Journal: Diaspora, Indigenous, and Minority EducationVolume 2, Issue 1, January 2008, pages 25-43

CABERO ALMENARA, Julio y ROMERO TENA, Rosalía. (coords.), Nuevas tecnologías en la práctica educativa, Granada, Arial, 2004

F. Javier Murillo \& Marcela Román, School infrastructure and resources do matter: analysis of the incidence of school resources on the performance of Latin American students, Journal: School Effectiveness and School ImprovementVolume 22, Issue 1, March 2011, pages 29-50

LITWIN, Edith (comp.), Tecnologías educativas en tiempos de Internet, Buenos Aires, Amorrortu Ediciones, 2005.

ANÁLISIS DE LA PROPUESTA DEL NUEVO BACHILLERATO, Presentada por el Ministerio de Educación, www. uasb. edu. ec, Enero 2011

Carlos Batista, Las TIC para la Gobernabilidad: La contribución de las Tecnologías de la Información y la Comunicación a la gobernabilidad local en América Latina, NP3 - Núcleo de Inves- 
tigación en Políticas Públicas, Universidad de Brasilia, Brasil, División de Desarrollo Social CEPAL

El portal educativo del Estado argentino http://portal. educ. ar/debates/educacionytic/nuevosalfabetismos/innovacion-utilizando-las-tics-para-el-aprendizaje-combinado. php

Enlaces. Centro de Educación y Tecnología, Ministerio de Educación [Chile], Educación y nuevas tecnologías - Desarrollo educativo - Mejora de la educación http:/ $/$ www. enlaces. cl/index. php?t $=44 \& \mathrm{i}=2 \& \mathrm{cc}=1171 \& \mathrm{tm}=2$

Guillermo Sunkel, LAS TECNOLOGÍAS DE LA INFORMACIÓN Y LA COMUNICACIÓN (TIC) EN LA EDUCACIÓN EN AMÉRICA LATINA. UNA EXPLORACIÓN DE INDICADORES

http://www. eumed. net/cursecon/ecolat/ec/2006/gvd. htm

Margarita Zorrilla, LA EDUCACIÓN SECUNDARIA EN MÉXICO: AL FILO DE SU REFORMA, REICE - Revista Electrónica Iberoamericana sobre Calidad, Eficacia y Cambio en Educación 2004, Vol. 2, No. 1 http://www. ice. deusto. es/rinace/reice/vol2n1/Zorrilla. pdf

Organización de Estados Iberoamericanos Para la Educación, Ciencia y la Cultura, http://www. oei. es/quipu/estadisticas. htm

PREAL, Orientaciones sobre TIC para la educación, Programa de Promoción de la Reforma Educativa en América Latina y el Caribe, Reforma de la educación - Políticas educativas ,http://www. preal. org/, 19/08/2011

Revista académica de economía con el Número Internacional Normalizado de Publicaciones Seriadas ISSN 1696-8352 